\title{
A CNS-targeting prodrug strategy for nuclear receptor modulators
}

\author{
Skylar J. Ferrara and Thomas S. Scanlan* \\ Department of Chemical Physiology and Biochemistry, Oregon Health \& Science University, 3181 SW Sam \\ Jackson Park Road, Portland, Oregon 97239, United States
}

KEYWORDS. prodrug, CNS, FAAH, nuclear receptors, blood-brain barrier

\begin{abstract}
The blood-brain barrier is a major impediment for targeted central nervous system (CNS) therapeutics, especially with carboxylic acid-containing drugs. Nuclear receptors modulators, which often feature carboxylic acid motifs for target engagement, have emerged as a class of potentially powerful therapeutics for neurodegenerative CNS diseases. Herein is described a prodrug strategy which directs the biodistribution of parent drug nuclear receptor modulators into the CNS while masking them as functional receptor ligands in the periphery. This prodrug strategy targets a specific amidase, fatty-acid amide hydrolase (FAAH), an enzyme with enriched expression in the CNS. Cleavage of the prodrugs by FAAH in the CNS substantially increases brain exposure and brain-to-serum ratios $\left(K_{p}\right)$, with increases up to $\sim 100$-fold compared to the $K_{p}$ of the systemically administered parent drug. Structure-activity relationships reveal that drug-like molecules with a linear shape are the best FAAH substrates, and comparisons of CNS vs peripheral drug-induced pharmacodynamics validate the CNS-selective distribution. Our results demonstrate that this prodrug strategy can be generalized to a variety of carboxylic acid-containing drug structures that satisfy the structural requirements of blood-brain barrier diffusion and FAAH substrate recognition.
\end{abstract}

\section{Introduction}

Nuclear receptors (NRs) are a validated class of drug targets and have recently emerged as potentially powerful targets for diseases of the central nervous system (CNS) ${ }^{1-5}$ These ligand-activated transcription factors are master regulators of vertebrate development as well as metabolism and homeostasis in adults, and their synthetic modulators encompass approximately $13 \%$ of FDA approved drugs. ${ }^{6-8} \mathrm{NR}$ signaling has been shown to control lipid turnover and homeostasis, induce differentiation or phenotypic changes of neurons and neuroglia, reduce amyloid burden, and suppress pro-inflammatory gene expression among other beneficial effects depending upon the particular receptor being activated. ${ }^{1-2,} 9$ Many NRs are expressed in CNS cell types linked to disease pathology enabling therapeutic intervention via modulation of key signaling pathways a promising strategy with these highly druggable target receptors.

Neurodegenerative CNS diseases remain challenging to target therapeutically due in part to the requirement that systemically dosed drugs pass through the blood-brain barrier (BBB), typically by passive diffusion. Endogenous nuclear receptor ligands such as thyroid hormone access the CNS from systemic circulation via active transport mechanisms. Many synthetic NR modulators, however, contain polar functional groups like 
carboxylates required for high-affinity target engagement. Anionic functionality such as carboxylates are a liability for passive diffusion across the BBB due to charge repulsion at the barrier surface and the unfavorable electrostatic energetics of the cellular membrane potential. Isosteric replacement of carboxylates can improve BBB penetration, but does not necessarily alter drug penetration into peripheral tissues where undesired or adverse drug effects may occur. To circumvent excessive peripheral exposure, a strategy favoring CNS distribution while minimizing peripheral drug exposure would be preferred.

A prodrug strategy that fulfills these criteria was recently developed in our lab for CNS-targeting of the synthetic thyromimetic drug sobetirome. ${ }^{10-11}$ We have used this strategy to increase sobetirome penetration into the CNS with mouse models of demyelination and lipid metabolism. ${ }^{12-13}$ This prodrug strategy is underpinned by two pivotal processes and entails (1) converting the drug's carboxylic acid functional group into an $N$-methyl amide which imparts beneficial physicochemical properties for BBB penetration via passive diffusion. As an amide, (2) the prodrug is a substrate for fatty acid amide hydrolase (FAAH), an amidase with enriched expression in the CNS that cleaves the amide prodrug into the carboxylate-containing parent drug. This results in enhanced CNS drug exposure and subsequent drug action (Figure $\mathbf{1 A}$ ), while at the same time minimizing parent drug exposure and action in the periphery.

FAAH is a membrane bound serine hydrolase expressed in the CNS and select peripheral tissues and functions to catabolize endogenous lipid endocannabinoids. ${ }^{14}$ Mice express only a single FAAH enzyme whereas humans express two, $\mathrm{FAAH}_{1}$ and $\mathrm{FAAH}_{2}$, and there is considerable sequence overlap between mouse $\mathrm{FAAH}$ and human $\mathrm{FAAH} 1$ with $84 \%$ shared amino acid identity. ${ }^{15}$ By targeting this specific enzyme, the prodrug remains masked in peripheral circulation and devoid of receptor activity. ${ }^{11}$ The $\mathrm{N}$-methyl amide of sobetirome proved to be the optimal amide for delivering the most sobetirome to the CNS from a systemic dose while at the same time minimizing the peripheral conversion of prodrug to parent drug. ${ }^{11}$ However, an open question remained as to whether this prodrug strategy could be successfully employed for other carboxylate drugs that may have therapeutic applications in the CNS. Given the similarities between mouse FAAH and human FAAH1, drugs adopting this prodrug strategy may prove useful as human therapeutics. Herein we describe the results from testing the FAAH-targeted prodrug strategy on a different known, and in some cases clinically relevant, carboxylic acid-containing nuclear receptor modulators. In doing so, the substrate capacity of FAAH is examined with respect to potential small molecule $N$-methyl amide substrates. 
A

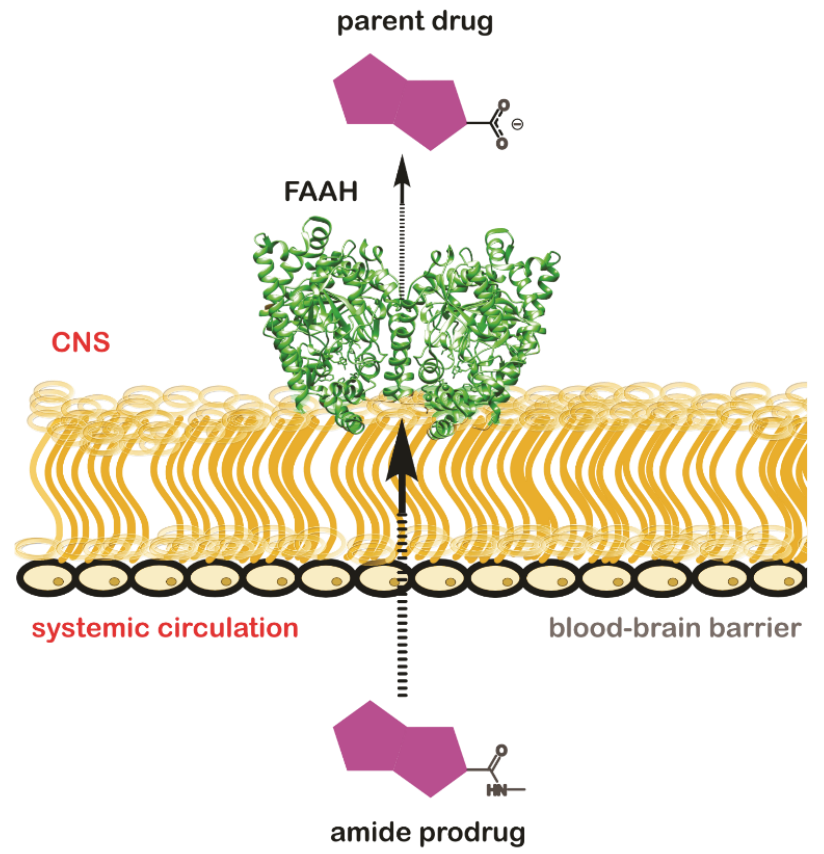

B

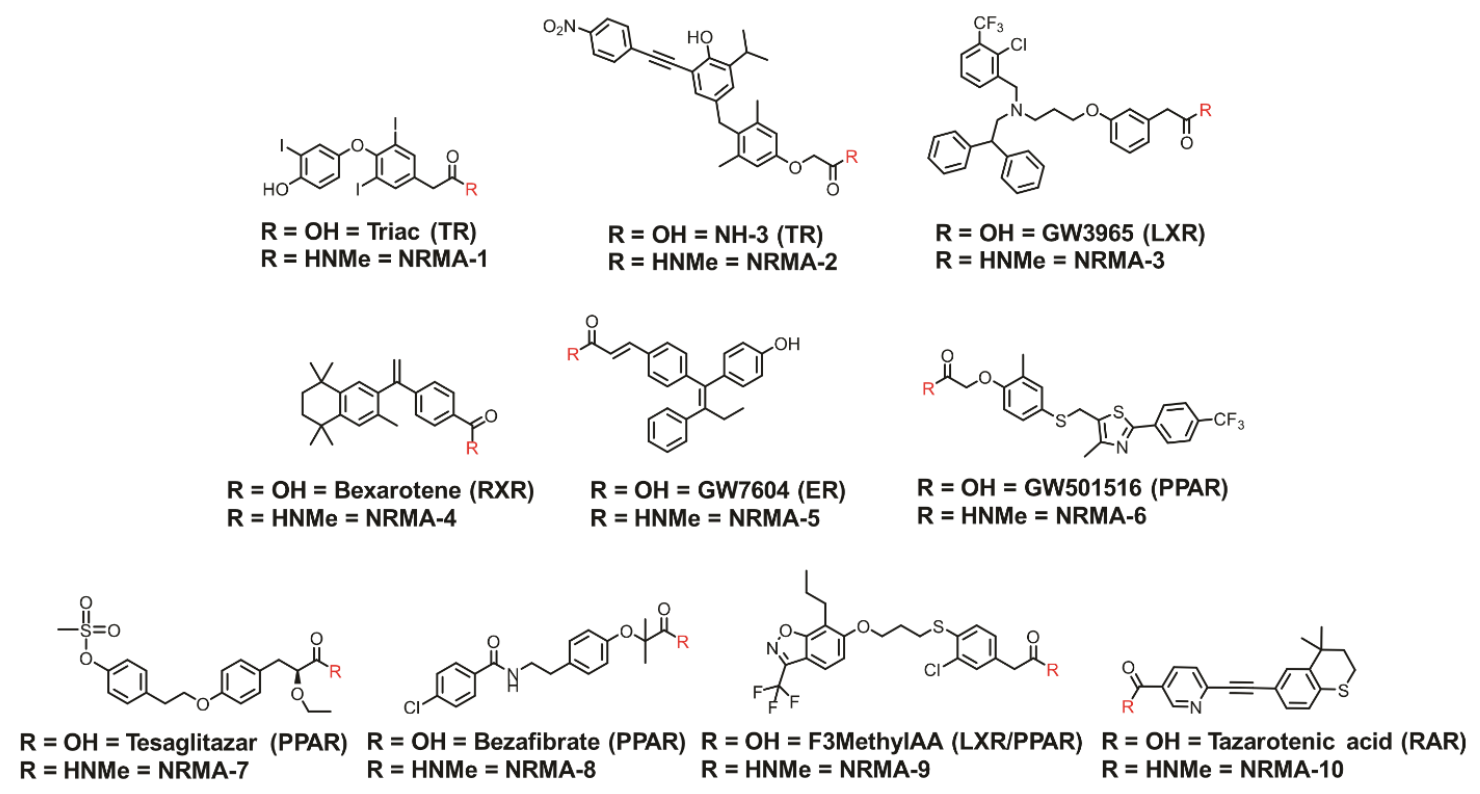

Figure 1:FAAH-targeting CNS-selective prodrug strategy $(\mathrm{A})$ and the series of nuclear receptor modulators with nuclear receptor target in parentheses, and their corresponding prodrugs NRMA 1-10 (B). 


\section{Results and Discussion}

\section{Prodrug strategy and structures}

Ten small molecule carboxylate-containing nuclear receptor modulators of therapeutic relevance to CNS disorders were chosen to test the generalizability of the FAAH-targeting prodrug strategy (Figure 1B). The panel includes ligands for thyroid hormone receptor (TR), retinoid $X$ receptor $(R X R)$, peroxisome proliferator-activated receptor (PPAR), liver $X$ receptor (LXR), estrogen receptor (ER), and retinoic acid receptor (RAR). Nuclear receptor ligands constitute a rather diverse set of molecules as a consequence of the differences in ligand binding pockets which correspond to the adapted biology of each receptor. ${ }^{16-17}$ Considerable structural variation is represented in this set of prodrug molecules to test the substrate capacity of FAAH with respect to small molecule drug-like structures. Each drug tested has sufficient drug-like properties and has undergone appropriate pharmacological evaluation to substantiate potential therapeutic utility in the CNS. ${ }^{18}$

The $N$-methyl amide motif featured in each prodrug was deliberately chosen because it was shown to be optimal for sobetirome, and represents the smallest (MW and size) practical amide moiety that increases lipophilicity while shrinking the molecule's topological polar surface area. ${ }^{11}$ These attributes promote the passive diffusion of the charge-neutral amide prodrug across the BBB. Installation of the $N$-methyl amide can be performed in a modular fashion via several routes. In our hands, CDI-mediated amide coupling proved the most suitable synthetic method given the range of solubility for the series and provided moderate to excellent yields of prodrug (see Experimental section).

\section{Prodrugs alter biodistribution and operate via FAAH in vivo}

To determine if the amide prodrugs favorably alter the biodistribution of parent drug into the CNS, parent drug concentrations were measured in brain and sera of male, wild-type $\mathrm{C}_{57} \mathrm{BL} / 6$ mice over 6 hours from the time of systemic administration (i.p., $9.14 \mu \mathrm{mol} / \mathrm{kg}$ ) to generate an area under the curve (AUC) (Figure 2,

Table 1). These AUC values represent brain and serum exposure of the parent drug, either from administration of the parent drug itself or that which was liberated via cleavage of the prodrug, over the 6 hour window and are used to calculate a brain-to-serum ratio $\left(K_{p}\right)$, a metric of CNS penetration and selectivity. Of the ten prodrugs tested, 6 prodrugs favorably altered the biodistribution toward the CNS and away from peripheral circulation. Compared to the corresponding parent drug, brain exposure increased 2-to-6-fold and brain-to-serum ratios were enhanced 2-to-94-fold (see Table 1). In particular, the prodrug of thyroid hormone receptor antagonist $\mathrm{NH}-3$, NRMA-2, displayed excellent selectivity with a 6.2-fold increase in brain exposure and a 94 -fold increase in $K_{p}$. In contrast, NRMA-1, the N-methyl amide of the other TR targeted drug Triac did not substantially increase CNS Triac exposure or Kp compared to unmodified Triac demonstrating SAR limits to the prodrug strategy with respect to TR ligands. The prodrugs of tazarotenic acid (NRMA-10) and tesaglitazar (NRMA-7), targeting RAR and PPAR, respectively, displayed $K_{p}$ improvements of 17 -fold and 15 -fold, respectively. Additionally, NRMA- 2 and NRMA-10 feature $K_{p}$ values of 1.5 and 2.03 , respectively, indicating preferred distribution to the CNS compared to the periphery. Moreover, the LC-MS/MS experiment to detect bezafibrate parent drug levels derived from NRMA8 was set up to include detection of 4 -chlorobenzoate in negative ion mode, the cleavage product resulting from hydrolysis of the bezafibrate core structure's internal amide. While NRMA-8 successfully altered parent drug partitioning to the CNS, no (<LoO) 4-chlorobenzoate was detected at any timepoint, suggesting that internal amides are precluded from hydrolysis during FAAH-mediated processing. These results demonstrate that the FAAH-targeted prodrug strategy can be extended to other carboxylate-containing drug scaffolds and the inclusion of internal amide functional groups are tolerated.

In contrast, the prodrugs for GW3965 (NRMA-3) and bexarotene (NRMA-4), targeting LXR and RXR, respectively, failed to yield quantifiable amounts of parent drug in brain and generated low levels in serum. This suggests that both prodrugs are not hydrolyzed to parent drug in the CNS or periphery, and instead are eliminated as the intact amide or an uncharacterized amide metabolite. Interestingly, the prodrugs for GW7604 
(NRMA-5) and F3MethylAA (NRMA-9), targeting ER and LXR, respectively, produced paltry, yet quantifiable concentrations of parent drug in brain and serum, however, the limited overall exposure of each is likely insufficient for any useful drug delivery purpose.

Table 1:List of parent drug and prodrug AUCs

\begin{tabular}{|c|c|c|c|}
\hline Compound (9.14 $\mu \mathrm{mol} / \mathrm{kg}$, i.p.) & Brain AUC $C_{0.5-6 h}(n g / g * h)$ & Serum $A \cup C_{0.5-6 h}(n g / g * h)$ & $\mathrm{K}_{\mathrm{p}}$ \\
\hline Triac & 88.9 & 5108 & 0.017 \\
\hline NRMA-1 & 155.8 & 4020 & 0.039 \\
\hline $\mathrm{NH}-3$ & 11.9 & 756.9 & 0.016 \\
\hline NRMA-2 & 73.8 & $49 \cdot 5$ & 1.5 \\
\hline GW 3965 & 1867 & 8853 & 0.21 \\
\hline NRMA-3 & $<$ LoO & 155.4 & - \\
\hline Bexarotene & 1910 & 1834 & 1.04 \\
\hline NRMA-4 & $<$ LoO & 4.933 & - \\
\hline GW7604 & 228.2 & 169.3 & 1.35 \\
\hline NRMA-5 & 18.03 & 17.77 & 1.01 \\
\hline GW501516 & 41.8 & 2330 & 0.018 \\
\hline NRMA-6 & 146.3 & 2705 & 0.054 \\
\hline Tesaglitazar & $7 \cdot 3$ & 2107 & 0.004 \\
\hline NRMA-7 & 21.9 & 374.1 & 0.06 \\
\hline Bezafibrate & $5 \cdot 5$ & 420.7 & 0.013 \\
\hline NRMA-8 & 26.3 & 470.6 & 0.06 \\
\hline F3MethylAA & 67.35 & 2140 & 0.03 \\
\hline NRMA-9 & 12.64 & 276.5 & 0.05 \\
\hline Tazarotenic acid & 38.5 & 314.5 & 0.12 \\
\hline NRMA-10 & 104 & 51.34 & 2.03 \\
\hline
\end{tabular}



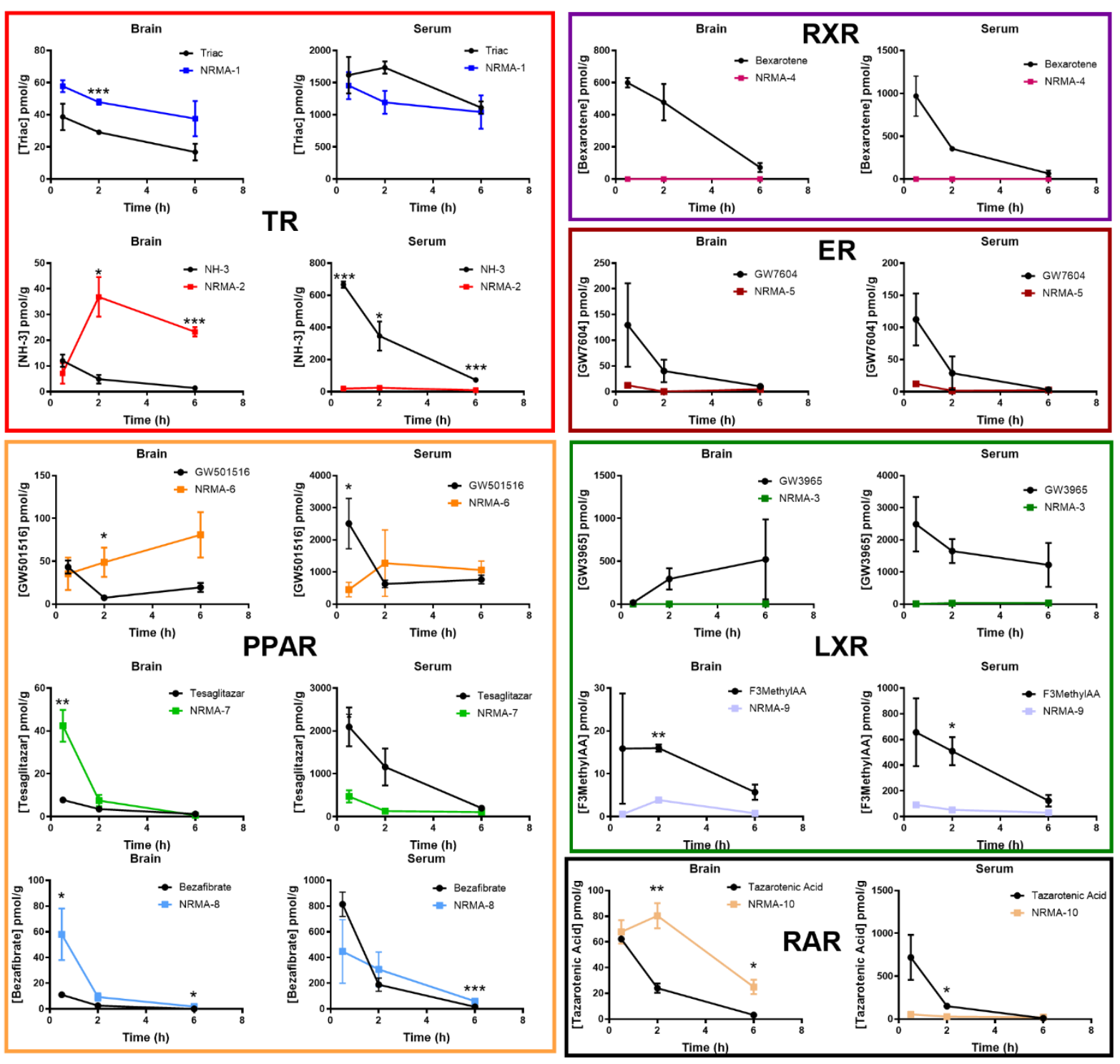

Figure 2: Side-by-side $6 \mathrm{~h}$ AUCs for brain and serum for the series of parent drugs and their corresponding prodrugs. Cohorts of male $\mathrm{C}_{57} \mathrm{BL} / 6$ mice $(n=3)$ were administered (i.p.) $9.14 \mu \mathrm{mol} / \mathrm{kg}$ parent drug or equimolar prodrug and tissues were collected at $0.5 \mathrm{~h}, 2 \mathrm{~h}$, and $6 \mathrm{~h}$ time points. Statistical significance was determined by a 2-tailed, unpaired $t$ test for comparisons between parent drug and prodrug at the same time point denoted with asterisks ( $* \mathrm{P} \leq 0.05, * * \mathrm{P} \leq 0.01, * * * \mathrm{P} \leq 0.001)$. All graphs show mean $\pm \mathrm{SEM}$.

To confirm FAAH as the critical hydrolase responsible for prodrug cleavage, FAAH inhibition experiments were performed using the FAAH inhibitor PF-3845 that inhibits FAAH in both the CNS and periphery from a systemic dose. ${ }^{19}$ Side-by-side comparisons of brain concentrations of nuclear receptor drug were analyzed from mice receiving either equimolar prodrug or $1 \mathrm{mg} / \mathrm{kg}$ PF-3845 followed by prodrug after 1 hour post-administration of the inhibitor (Figure 3). Mice receiving only prodrug displayed high concentrations of parent drug in the brain, while those that received prodrug and FAAH inhibitor generally showed diminished prodrug-to-parent drug conversion. Differences in parent drug levels were observed between each pair except for those prodrugs which weren't cleaved in vivo, suggesting the prodrugs are hydrolyzed specifically by FAAH in the brain. However, 
NRMA-1, and to a much lesser extent NRMA-6, produced significant quantities of parent drug in the brain in the presence of the FAAH inhibitor. This indicates promiscuous cleavage of these prodrugs likely in peripheral circulation prior to distribution into the CNS by hydrolases other than FAAH, which corroborates with the relatively high serum drug levels observed in the AUCs following systemic administration (Table 1).

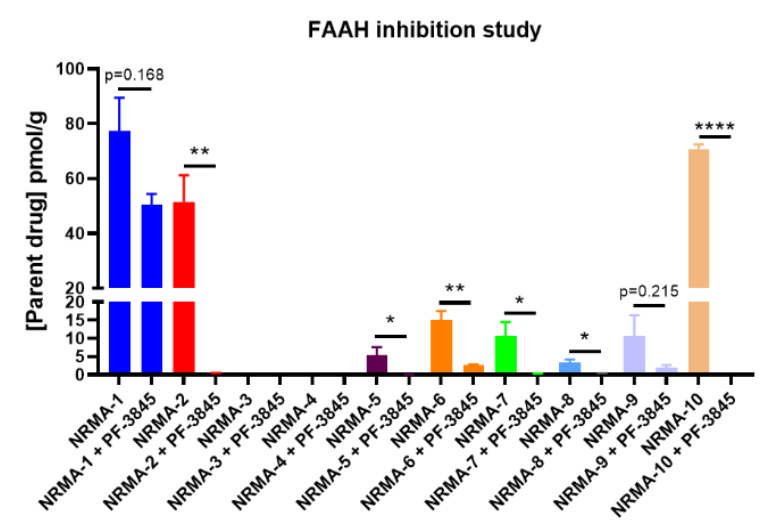

Figure 3: Comparison of cleaved parent drug levels in brain with or without the presence of global FAAH inhibitor PF-3845 $1 \mathrm{~h}$ post-dose. Cohorts of male $\mathrm{C} 57 \mathrm{BL} / 6$ mice $(\mathrm{n}=3)$ were administered (i.p.) $9.14 \mu \mathrm{mol} / \mathrm{kg}$ prodrug or 1 $\mathrm{mg} / \mathrm{kg}$ PF-3845 followed by $9.14 \mu \mathrm{mol} / \mathrm{kg}$ prodrug after $1 \mathrm{~h}$, then brain tissue was collected $1 \mathrm{~h}$ after prodrug administration. Statistical significance was determined by a 2 -tailed, unpaired $t$ test for comparisons between prodrug groups with and without receiving FAAH inhibitor and is denoted with asterisks (*P $\leq 0.05, * * P \leq 0.01$, $* * * P \leq 0.001, * * * * P \leq 0.0001)$. All graphs show mean $\pm \mathrm{SEM}$.

\section{FAAH hydrolysis and SAR}

In an effort to extrapolate information regarding FAAH's substrate capacity with respect to these druglike structures and how that relates to what makes a suitable prodrug, characterization of in vitro FAAH hydrolysis rates were determined (Figure $4 \mathrm{~A}$ ). Within the series, FAAH cleavage rates using a mouse liver S9 fraction ranged from $\sim 1$ to $>300 \mathrm{pmol}^{*} \mathrm{mg}^{-1} \mathrm{~min}^{-1}$. NRMA- 6 and NRMA-1 were found to be cleaved the fastest, which mirrors their rather facile peripheral cleavage following systemic administration previously observed in the AUC study. Somewhat surprisingly, the prodrugs which altered the brain-to-serum ratio to the greatest extent had among the slowest FAAH hydrolysis rates at only about 1-2 pmol* $\mathrm{mg}^{-1} \mathrm{~min}^{-1}$. In fact, a negative correlation was observed between FAAH hydrolysis rate and $\Delta K_{p}$, the change in brain-to-serum ratio from parent drug to prodrug (Figure 4B). These data suggest that prodrugs which survive peripheral circulation, likely due to their ability to act as poor substrates for FAAH expressed in the liver (or periphery in general) - yet substrates nonetheless, allows for a greater fraction of prodrugs to segregate into the CNS for cleavage by FAAH expressed in the CNS. In this way, the in vitro hydrolysis rate may serve as a potential indicator for the CNS selectivity of a particular prodrug. Hydrolysis rates using a human brain $\mathrm{S} g$ fraction as the source of FAAH were also collected and recapitulate the results found in mouse liver $\mathrm{S} g$ fractions, however greater FAAH activity was generally observed in mouse liver compared to human brain (Figure ${ }_{4} \mathrm{C}$ ). Additionally, there was an observed increase in NRMA-8 cleavage and a decrease in NRMA-g cleavage in human brain S 9 fraction compared to mouse liver S 9 fraction. Nevertheless, the human brain Sg fraction activity generally validates the translational potential of this prodrug strategy for use with human therapeutics. 


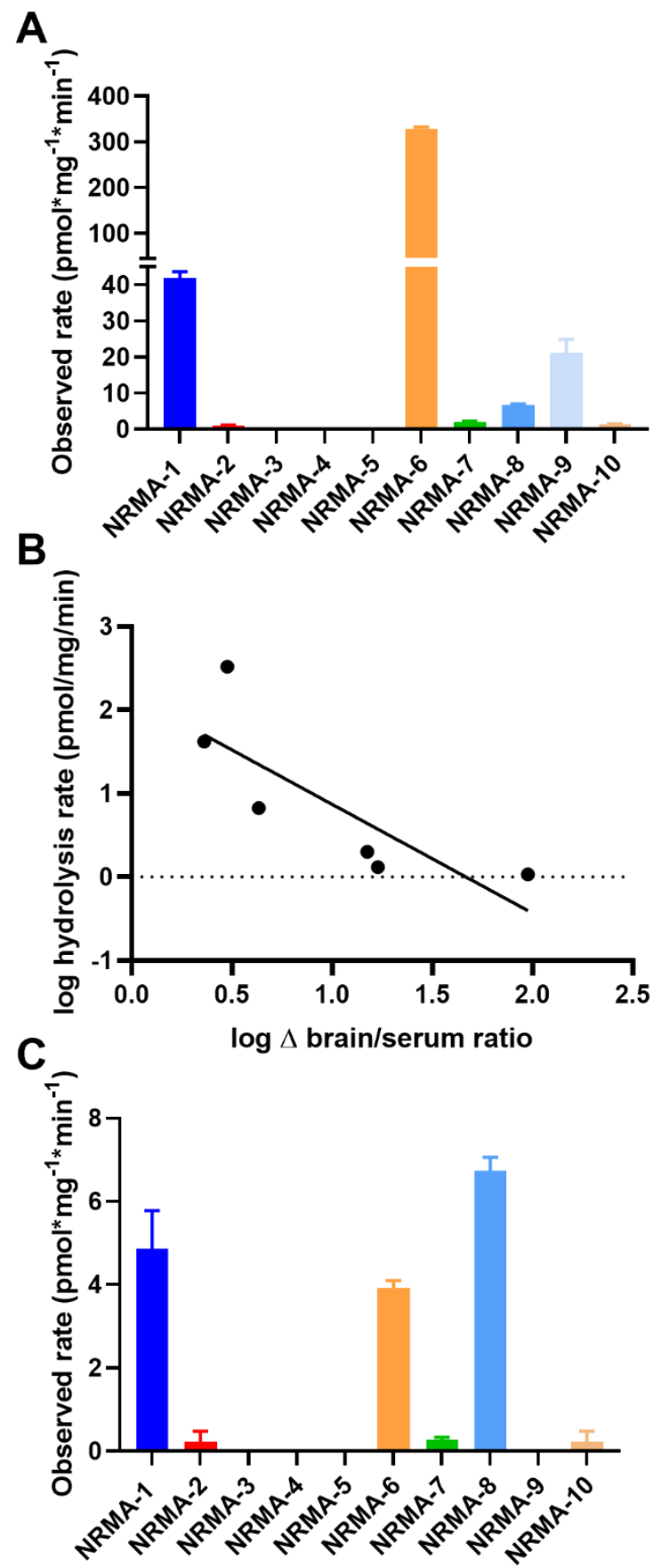

Figure 4: In vitro FAAH hydrolysis rates for the series of prodrugs in mouse liver $\mathrm{S} g$ fraction (A) and human brain $\mathrm{Sg}$ fraction (C). Trending relationship between in vitro hydrolysis rates and CNS-selectivity from AUC data (vide supra, Figure 2) for $\mathrm{C}_{57} \mathrm{BL} / 6$ mice (B).

Structure-activity relationships were analyzed to understand why certain prodrugs are not cleaved efficiently by FAAH. Basic physicochemical properties like MW, lipophilicity, topological polar surface area, number of rotatable bonds etc., failed to exhibit any sort of rational correlation with the prodrug CNS distribution 
data (see boiled egg plot SI Figure S1). However, analysis of each prodrug's molecular shape elucidated a connection between structure and CNS distribution of the parent drug. Principal moments of inertia (PMI) calculations on molecular mechanics optimized structures can afford a two-dimensional PMI plot which triangulates the overall shape of a particular molecule (Figure 5). ${ }^{17,20}$ Prodrugs that displayed CNS selectivity within this series which was inhibited by FAAH inhibitor PF-3845, all reside close to the vertex which represents linear, rod-like structures. Those prodrugs not cleaved appreciably by FAAH deviate from linearity and spread closer toward the flat, disc-like molecular space, and to a lesser extent, the spherical vertex. This PMI plot shows the preference for linear structures as acceptable substrates for FAAH, disfavoring those with more exaggerated or branched three-dimensional structures (NRMA-3, 4, and 5). As the endogenous substrates for FAAH are amides of fatty acids, it's logical that prodrugs with structural similarities to fatty acids would make admissible substrates within FAAH's active site. This trend was recognized prior to the completion of the series of prodrugs, and NRMA9 and NRMA-10 were synthesized and studied to validate this structural preference. Unlike the highly branched LXR agonist prodrug NRMA-3, NRMA-9 is an LXR agonist prodrug that features a slimmer, more linear shape. Although NRMA-9 did not alter the biodistribution of its corresponding parent drug in a usable manner, it did lead to small, but measurable levels of cleaved parent drug in contrast to NRMA-3. Moreover, inclusion of NRMA-10 led to a bona fide CNS-selective prodrug with a $\mathrm{K}_{\mathrm{p}}$ of 2.03 , thus validating molecular shape as the critical property which defines substrate capacity for FAAH. For practical use as a predictor, molecules with $\mathrm{PMI} \mathrm{I}_{1} / \mathrm{l}_{3}<0.2$ and PMI $\mathrm{I}_{2} / \mathrm{I}_{3}>0.9$ appear to make suitable substrates for FAAH, at least as defined within this series.

\section{PMI Plot}

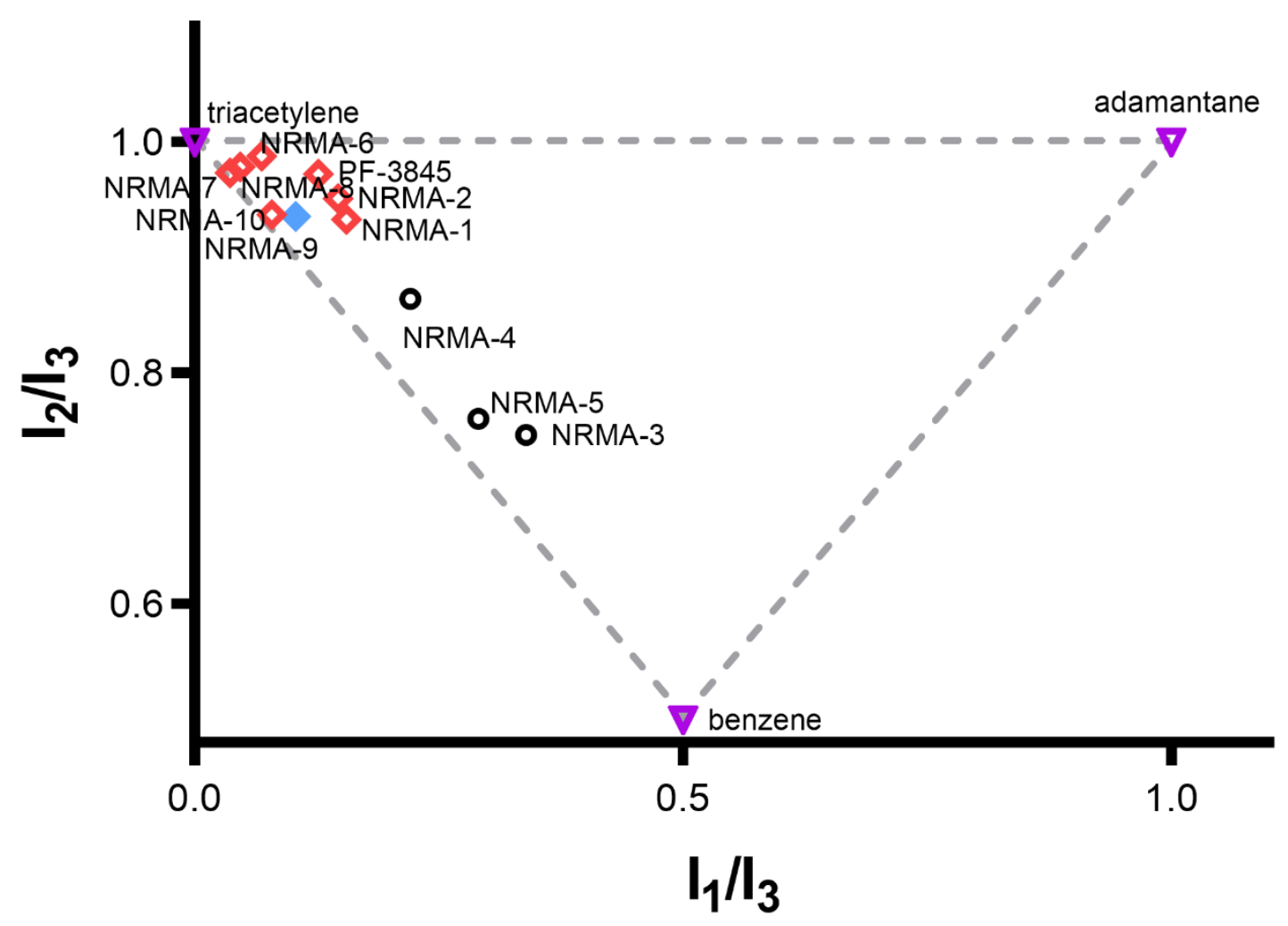

Figure 5: Principal moments of inertia plot for the prodrug series including FAAH inhibitor PF-3845 demonstrating the molecular shape preference for acceptable FAAH substrates aggregating toward the linear, rod-like shape vertex (top left). 


\section{Proof of concept: CNS vs peripheral effects}

To validate that increased CNS exposure and decreased peripheral exposure lead to the appropriate transcriptional responses, an experiment to quantify target gene expression from the brain and peripheral tissues was performed. Cohorts of male $\mathrm{C}_{57} \mathrm{BL} / 6$ mice were dosed once daily for seven days with either parent drug, equimolar prodrug, or vehicle to compare target gene expression levels between groups per tissue. NRMA-7 and NRMA-10 were chosen to study due to their exceptional CNS distribution properties, with 15 -fold and 17 -fold increases in $K_{p}$ relative to their corresponding parent drugs, respectively. NRMA- 7 is the prodrug of dual PPAR $\gamma / \alpha$ agonist tesaglitazar, and PPAR $\gamma$ agonists have been shown to protect dopaminergic neurons and reduce amyloid plaque burden. ${ }^{21-24}$ However, tesaglitazar failed in clinical trials due to renal and cardiac safety issues, making tesaglitazar an ideal candidate for a drug that may benefit from this prodrug strategy..$^{25-26}$ Indeed, after seven days of dosing prodrug NRMA-7 was shown to significantly upregulate the PPAR target gene Pgc1- $\alpha$ (PPAR gamma coactivator 1 alpha) in the brain, while having no effect on expression of Fasn (fatty acid synthase) in the kidney (Figure 6C+D). In contrast, administration of the unmodified parent drug tesaglitazar showed no effect on Pgc1- $\alpha$ in the brain, but downregulated kidney Fasn. Tazarotenic acid, the parent drug of prodrug NRMA-10, is a pan-RAR agonist which positively regulates the main alpha secretase Adamio responsible for amyloid precursor protein processing. ${ }^{27}$ Seven days of treatment with tazarotenic acid does not significantly upregulate target brain gene Adam10, however, the corresponding prodrug NRMA-10 does increase brain expression of Adam10.

Conversely, tazarotenic acid treatment upregulates the liver target gene Rarres2, while NRMA-10 had no effect (Figure 6A+B). ${ }^{28}$ As predicted, the CNS selectivity of these prodrugs affords greater exposure and subsequent target engagement in the CNS while attenuating exposure and target engagement in the periphery. In this way, these prodrugs offer not only greater on-target potency in the CNS, but also less potential on-target adverse effects in the periphery resulting in a larger therapeutic index.
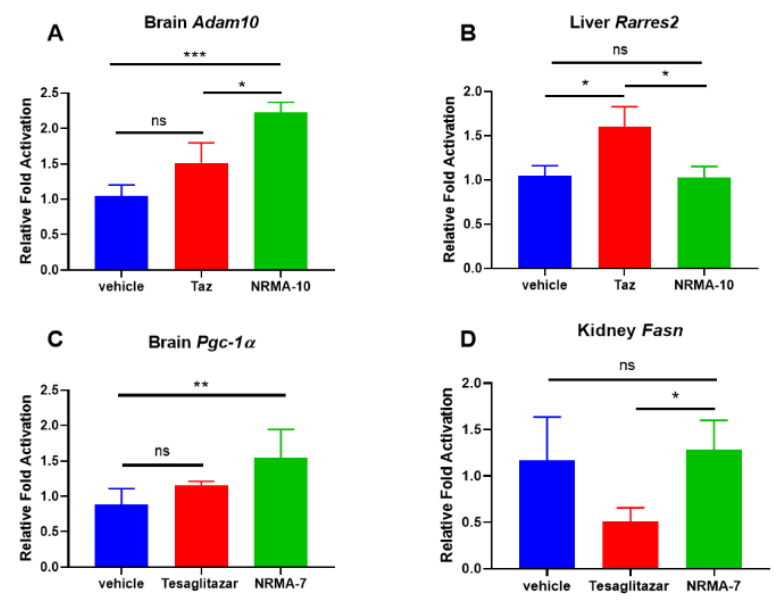

Figure 6: RT-qPCR comparisons between administered parent drug and prodrug for CNS and peripheral tissue genes. Cohorts of male $\mathrm{C} 57 \mathrm{BL} / 6$ mice $(n=5)$ were administered (i.p.) $9.14 \mu \mathrm{mol} / \mathrm{kg}$ parent drug, equimolar prodrug, or vehicle for 7 days once daily by i.p. Statistical significance was determined by a 2 -tailed, unpaired $t$ test for comparisons between groups with asterisks $(* P \leq 0.05, * * P \leq 0.01, * * * P \leq 0.001)$. All graphs show mean $\pm \mathrm{SEM}$.

\section{Conclusions}

This study demonstrates that CNS-selective distribution of drugs can be achieved utilizing a FAAHtargeted prodrug strategy. In order to successfully implement: 1) the parent drug must contain a carboxylic acid functional group; 2 ) the parent drug must have sufficient drug-like properties and largely obey Lipinski's Rule of 5 to facilitate passive diffusion of the prodrug across the BBB; 3 ) conversion of the parent drug's carboxylic acid to 
an amide defines the prodrug; 4 ) the newly generated amide prodrug must have an overall linear shape as defined by PMI calculations $\left(\mathrm{PMI} \mathrm{I}_{1} / \mathrm{l}_{3}<0.2\right.$ and $\mathrm{PMI} \mathrm{I}_{2} / \mathrm{l}_{3}>0.9$ ). Additionally, we find that prodrugs with slower in vitro FAAH-mediated hydrolysis rates $\left(<5 \mathrm{pmol}^{*} \mathrm{mg}^{-1} \mathrm{~min}^{-1}\right.$ in this experiment in mice) provided the highest degree of CNS selectivity, presumably by avoiding peripheral FAAH cleavage in the liver and/or gut. Given that this prodrug strategy is generalizable to carboxylate-containing drugs other than sobetirome, this blueprint should find utility within the fields of drug discovery and neuroscience and facilitate the development of new CNS drugs and tool compounds.

\section{Experimental Section}

\section{Parent drug abbreviations}

All parent drugs were purchased from commercial sources with the exception of $\mathrm{NH}-3$ which was synthesized in our laboratory. ${ }^{29}$

Triac $=[4-(4$-hydroxy-3-iodophenoxy)-3,5-diiodophenyl]acetic acid

$\mathrm{NH}-3=2-(4-(4$-hydroxy-3-isopropyl-5-((4-nitrophenyl)ethynyl)benzyl)-3,5-dimethylphenoxy)acetic acid

GW3965 = 2-(3-(3-((2-chloro-3-(trifluoromethyl)benzyl)(2,2-diphenylethyl)amino)propoxy)phenyl)acetic acid

Bexarotene $=4-(1-(3,5,5,8,8$-pentamethyl-5,6,7,8-tetrahydronaphthalen-2-yl)vinyl) benzoic acid

GW7604 = (E)-3-(4-((E)-1-(4-hydroxyphenyl)-2-phenylbut-1-en-1-yl)phenyl)acrylic acid

GW501516 = 2-(2-methyl-4-(((4-methyl-2-(4-(trifluoromethyl)phenyl)thiazol-5-yl)methyl)thio)phenoxy)acetic acid

Tesaglitazar $=(\mathrm{S})-2$-ethoxy-3-(4-(4-((methylsulfonyl)oxy)phenethoxy)phenyl)propanoic acid

Bezafibrate $=2-(4-(2-(4-$ chlorobenzamido)ethyl)phenoxy $)-2-$ methylpropanoic acid

F3MethylAA = 2-(3-chloro-4-((3-((7-propyl-3-(trifluoromethyl)benzo[d]isoxazol-6-yl)oxy)propyl)thio)phenyl)acetic acid

Tazarotenic acid = 6-((4,4-dimethylthiochroman-6-yl)ethynyl)nicotinic acid

\section{Animal Studies}

Experimental protocols were in compliance with the National Institutes of Health Guide for the Care and Use of Laboratory Animals and approved by the Oregon Health \& Science University Institutional Animal Care \& Use Committee. Wild-type C57BL/6 mice, aged 8-10 weeks, were purchased from Jackson Laboratory and all mice were housed in climate-controlled rooms with a $12 \mathrm{~h} / 12 \mathrm{~h}$ light-dark cycle with ad libitum access to food and water. FAAH-KO mice on a C57/BL6 background were a kind gift of Prof. Benjamin Cravatt (Scripps Research Institute)..$^{30}$ All injections were delivered intraperitoneally (i.p.) using DMSO as a vehicle except for chronic 7 day once-daily injections which used a 1:1:8 Kolliphor:NMP:water vehicle. Injection volumes were standardized to 150 $\mu \mathrm{L} / 26 \mathrm{~g}$ mouse weight. FAAH inhibitor PF-3845 was purchased from Sigma-Aldrich and was used as received.

\section{Tissue Processing}

Tissues were processed for LC-MS/MS analysis as previously described with slight modifications. ${ }^{10,{ }^{31}}$ Standard curves were prepared in vehicle treated samples for each tissue to control for ion suppression in the analysis. In each run, tissue from a vehicle treated mouse was brought through the stages of processing and split to generate a standard curve using known concentrations of each parent drug. Deuterated $d_{6}$-sobetirome was used as an internal standard in each sample due to its robust and well-known behavior regarding extraction recovery, ionization response, and chromatographic retention time. ${ }^{29}$

Serum. Whole blood was incubated for $15 \mathrm{~min}$ on ice and then spun at $7,800 \mathrm{rpm}$ for $15 \mathrm{~min}$ at $4^{\circ} \mathrm{C}$. Serum $(100 \mu \mathrm{L})$ was transferred to a new tube and stored at $-80^{\circ} \mathrm{C}$ until further processed. Serum samples were thawed on ice prior to treatment with $10 \mu \mathrm{L}$ of internal standards ( $2.99 \mu \mathrm{M} d_{6}$-sobetirome in DMSO) followed by a crash with 125 $\mu \mathrm{L}$ of EtOAc followed by $400 \mu \mathrm{L}$ of $\mathrm{MeCN}$. Following a vigorous vortexing for $20 \mathrm{~s}$, samples were centrifuged at $10,000 \mathrm{rpm}$ for $15 \mathrm{~min}$ at $4^{\circ} \mathrm{C}$. The supernatant is dried under high vacuum, then samples were treated with 400 
$\mu \mathrm{L} 10 \% \mathrm{DMF}$ in MeCN with vigorous vortexing. Samples were transferred to eppendorf tubes, centrifuged at $10,000 \mathrm{rpm}$ for $15 \mathrm{~min}$ at $4^{\circ} \mathrm{C}$, and the supernatant was transferred and centrifuged again at $13,000 \mathrm{rpm}$ for $15 \mathrm{~min}$ at $4^{\circ} \mathrm{C}$ prior to analysis by LC-MS/MS.

Brain. Tissue weights were determined prior to homogenization. Whole brains were added to $1 \mathrm{~mL}$ of water containing $10 \mu \mathrm{L}$ internal standard (2.99 $\mu \mathrm{M} \mathrm{d} d_{6}$-sobetirome) in $2 \mathrm{~mL}$ tubes containing 3 GoldSpec $1 / 8$ chrome steel balls (Applied Industrial Technologies) and tissues were homogenized using a Bead Ruptor 24. The homogenate was crashed and extracted with $1 \mathrm{~mL}$ of EtOAc and $4 \mathrm{~mL}$ of MeCN, then centrifuged at 10,000 rpm for 15 min at 4 ${ }^{\circ} \mathrm{C}$. The supernatant was transferred to glass culture tubes and dried under high vacuum. The sample residue was then treated with $400 \mu \mathrm{L}$ of $10 \% \mathrm{DMF}$ in MeCN and vigorously vortexed for $20 \mathrm{~s}$. The sample was transferred to an eppendorf tube and centrifuged at $10,000 \mathrm{rpm}$ for $15 \mathrm{~min}$ at $4^{\circ} \mathrm{C}$. The resulting supernatant was transferred again and was centrifuged at $13,000 \mathrm{rpm}$ for $15 \mathrm{~min}$ at $4^{\circ} \mathrm{C}$ and submitted for LC-MS/MS analysis.

Liver and Kidney. Liver and kidney tissues were processed exactly as brain tissue above.

\section{LC-MS/MS Analysis}

Prodrugs and internal standard were analyzed using a QTRAP 4000 hybrid/triple quadrupole linear ion trap mass spectrometer (Applied Biosystems, (Foster City, CA)) with electrospray ionization (ESI) in negative mode. The mass spectrometer was interfaced to a Shimadzu (Columbia, MD) SIL-20AC XR auto-sampler followed by 2 LC$20 A D X R L C$ pumps and column oven. The mass spectrometer was operated with the following settings: source voltage -4500 kV, GS1 30, GS2 40, CUR 10, TEM 650, and CAD MEDIUM. The scheduled MRM transitions monitored are listed in the Supporting Information (Table S2). Compounds were infused individually, and instrument parameters optimized for each MRM transition. The column was a $3 \mu \mathrm{m}$ Gemini-NX C18 $50 \times 2.1 \mathrm{~mm}$, kept at $40^{\circ} \mathrm{C}$. The autosampler was kept at $15^{\circ} \mathrm{C}$. The gradient mobile phase was delivered at a flow rate of 0.75 $\mathrm{ml} / \mathrm{min}$, and consisted of two solvents, A: $0.1 \%$ formic acid in water and B: $0.1 \%$ formic acid in acetonitrile. The gradient was as follows: initial concentration of B was $10 \%$, held for 1 minute, followed by an increase to $95 \%$ B over 5 minutes, held for 2 minutes, returning to $10 \% \mathrm{~B}$ over 0.1 minutes, and held at $10 \% \mathrm{~B}$ for 3 minutes for a total run time of 11 minutes. Column eluant was directed to the ionization source from 0.5 minutes to 8 minutes. Data were acquired using Analyst 1.6.2 software and analyzed using Multiquant 3.0.2.

\section{$R T-q P C R$}

RNA was purified using the PureLink RNA Mini kit with TRIzol extraction (Life Technologies, for whole brain, liver, and kidney). RNA was quantified using a Nanodrop, and CDNA was prepared with the QuantiTect Reverse Transcription kit (Qiagen). Each qPCR experiment was performed on an Applied Biosciences 7500 Real-Time PCR system using and following the QuantiTect SYBR Green PCR kit protocols (Qiagen). Results were analyzed using the $\triangle \triangle \mathrm{Ct}$ relative quantification. ${ }^{22}$ Experiments were performed using primers for the housekeeping gene cyclophilin A (f-Ppia: 5'-AGGGTGGTGACTTTACACGC-3'; r-Ppia: 5'-CTTGCCATCCAGCCATTCAG-3'), and target gene primers PPAR gamma coactivator 1- $\alpha$ (f- Pgc-1a 5'-TGAGAGGGCCAAGCAAAG-3', r- Pgc-1a 5'ATAAATCACACGGCGCTCTT-3'), A disintegrin and metalloproteinase domain-containing protein 10 (f-Adam10 5'-GGGAAGAAATGCAAGCTGAA-3', r-Adam10 5'-CTGTACAGCAGGGTCCTTGAC-3'), Rarres2 (chemerin) (f-Rarres2 5'-TACAGGTGGCTCTGGAGGAGTTC-3', r-Rarres2 5'-CTTCTCCCGTTTGGTTTGATTG-3'), and fatty acid synthase (f-Fasn 5'-GCTGCTGTTGGAAGTCAGC-3', r-Fasn 5'-AGTGTTCGTTCCTCGGAGTG-3').33-37

\section{In Vitro FAAH Hydrolysis Assays}

S9 subcellular fractions derived from WT $\mathrm{C}_{57} \mathrm{BL} / 6$ and FAAH KO mouse livers were isolated as previously described and diluted into TE buffer ( $50 \mathrm{mM}$ Tris HCl, $1 \mathrm{mM} \mathrm{EDTA}, 3 \mathrm{mM} \mathrm{MgCl}, \mathrm{pH} 7.4$ ) to $1 \mathrm{mg} / \mathrm{ml} .3^{8} \mathrm{Human}$ brain $\mathrm{S} g$ fractions were purchased commercially from Sekisui XenoTech (Kansas City, Kansas). Protein concentrations were measured using a BCA protein assay (Pierce). 
For observed rates, $49 \mu \mathrm{L}$ of Sg fraction at $1 \mathrm{mg} / \mathrm{mL}$ (WT mouse, FAAH KO mouse, human brain, or human brain containing $10 \mu \mathrm{M}$ PF-3845) was prewarmed at $37^{\circ} \mathrm{C}$ in a water bath for $5 \mathrm{~min}$, followed by the addition of $1 \mu \mathrm{L}$ of 5 $\mathrm{mM}$ prodrug (working concentration of $100 \mu \mathrm{M}$ ) or DMSO vehicle and briefly vortexed. These mixtures were incubated at $37^{\circ} \mathrm{C}$ for 15 min then crashed with $250 \mu \mathrm{L}$ of $29.9 \mathrm{nM} \mathrm{d} d_{6}$-sobetirome internal standard in $10 \%$ DMF in $\mathrm{MeCN}$, vortexed, and centrifuged at $10,000 \mathrm{rpm}$ for $15 \mathrm{~min}$ at $4^{\circ} \mathrm{C}$. Samples were prepared from this supernatant fresh immediately prior to submission for LC-MS/MS as described above. For each prodrug, concentrations were determined from: [WT liver S9 sample $(n=3)$ - average of FAAH KO liver S9 samples $(n>2)$ ] or [human brain S9 sample ( $n=3)$ - average of human brain S9 samples containing $10 \mu \mathrm{m}$ PF-3845 (n>2)]. In each run, a single S9 fraction containing $1 \mu \mathrm{L}$ DMSO vehicle instead of prodrug was split and used to generate the standard curve.

\section{PMI calculations and Plot}

Principal moments of inertia (PMI) for each molecule were calculated using Chem3D (Version 15.1.0.144, Perkin Elmer). Chemical structures drawn in ChemDraw (Perkin Elmer) were brought into Chem3D and an MM2 energy minimization was performed. On this minimized structure, principal moments of inertia were calculated to afford three values which correspond to the principal 'vectors' of the molecule $I_{1}, I_{2}$ and $I_{3}$. The two shorter vectors $\left(I_{1}\right.$ and $I_{2}$ ) are each divided by the longest vector $\left(I_{3}\right)$ and plotted on a two-dimensional graph (PMI plot). Vertices are represented by 1,3,5-hexatriyne (triacetylene), benzene, and adamantane to describe the molecular shapes as linear and rod-like, flat and disc-like, and round/spherical, respectively. All molecules calculated fall within this triangular plot which characterizes each molecule's shape.

\section{Statistical Analysis}

Statistical significance was determined using 2-tailed, unpaired $t$ tests for comparisons between two specific groups then plotted together as indicated. Replicates in each experiment were as stated in the specific figure legend and in the corresponding methods. Experimental numbers for animal experiments were informed by previous literature accounts in order to minimize total animal numbers as appropriate. Analysis was carried out in GraphPad Prism 7 without further modifications. Significance level was set to $* P \leq 0.05, * * P \leq 0.01, * * * P \leq 0.001$, $* * * * \mathrm{P} \leq 0.0001$. All graphs show mean $\pm \mathrm{SEM}$.

\section{General Chemistry}

${ }^{1} \mathrm{H}$ NMR were taken on a Bruker $400 \mathrm{MHz}$ spectrometer. All spectra were calibrated to the chloroform $\mathrm{CDCl}_{3} \mathrm{NMR}$ solvent reference peak. ${ }^{1} \mathrm{H}$ coupling constants $\left(\mathrm{J}_{\mathrm{HH}}, \mathrm{Hz}\right)$ are reported as follows: chemical shift, multiplicity $(\mathrm{br}=$ broad, $s=$ singlet,$d=$ doublet, sept = septet, $m=$ multiplet, $d d=$ doublet of doublets), coupling constant, and integration. High resolution mass spectrometry (HRMS) with electrospray ionization was performed by the Bioanalytical MS Facility at Portland State University. $d_{6}$-sobetirome was synthesized as previously described. ${ }^{29}$ All other reagents were purchased from Fisher, Sigma, or TCl and used as received. Analytical HPLC analysis was performed on a Varian ProStar HPLC with a Grace Altima C18, $5 \mu \mathrm{m}$ column $(4.6 \mathrm{~mm} \times 250 \mathrm{~mm}$ ) with a gradient (solvent $A=$ water $+0.1 \%$ TFA; solvent $B=M e C N+0.1 \%$ TFA) over 30 mins. with a flow rate of $1 \mathrm{~mL} / \mathrm{min}$. Purity analysis of final compounds was determined to be $>95 \%$ by HPLC $\left(A_{235} \mathrm{~nm}\right)$.

\section{Synthetic scheme}

1) $\mathrm{CDI}$<smiles>[Y]C(=O)O</smiles>

dry THF, $50^{\circ} \mathrm{C}$
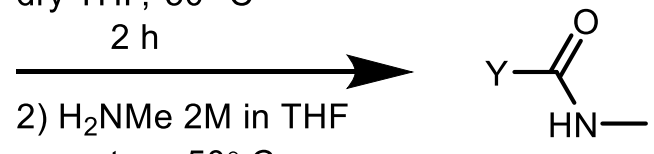

r.t. $\rightarrow 50^{\circ} \mathrm{C}$

$16 \mathrm{~h}$ 
A modular synthesis of prodrug $\mathrm{N}$-methyl amides was developed. Activation of the parent drug carboxylic acid with carbonyldiimidazole (CDI) followed by the addition of excess methylamine in THF provides the N-methyl amide prodrugs in moderate-to-good yields. The advantage of this method relates to the mild conditions for amide coupling of these rather expensive parent drug starting materials, which typically generates product mixtures that are only amide product and starting material after work-up.

\section{General synthetic procedure}

$35 \mathrm{mg}$ (1 equivalent) of parent drug carboxylic acid was placed in a thick-walled tube containing carbonyldiimidazole (CDI, 1.2 equivalents), a stir bar, and $3 \mathrm{~mL}$ of dry THF. The tube was sealed, placed under vacuum, then refilled with argon three times. While under argon, the mixture was heated for $2 \mathrm{~h}$ at $50^{\circ} \mathrm{C}$ then cooled to room temperature. Three additional vacuum/argon refills were performed followed by the addition of excess methylamine ( 10 equivalents, $2 \mathrm{M}$ in THF) via syringe. The mixture was stirred at room temperature for 2 $\mathrm{h}$, then heated to $50^{\circ} \mathrm{C}$ for $\sim 14 \mathrm{~h}$. Upon cooling, the product mixture was diluted with dichloromethane and washed with $1 \mathrm{~N} \mathrm{HCl}$ and brine. All organic layers were combined, dried with sodium sulfate, and evaporated to dryness to give the crude product mixture typically containing only starting material and product by TLC. The product was separated on silica with 1-10\% $\mathrm{MeOH}$ in DCM usually as the first band.

\section{NRMA-1}

\section{2-(4-(4-hydroxy-3-iodophenoxy)-3,5-diiodophenyl)-N-methylacetamide}

$35 \mathrm{mg}$ triac $(0.056 \mathrm{mmol})$ yielded $30.45 \mathrm{mg}(0.048 \mathrm{mmol}, 87 \%)$ product as an off-white powder.

${ }^{1} \mathrm{H}$ NMR $(400 \mathrm{MHz}$, Chloroform-d) $\delta 7.78(\mathrm{~s}, 2 \mathrm{H}), 7.10(\mathrm{dd}, J=2.9,1.1 \mathrm{~Hz}, 1 \mathrm{H}), 6.94-6.87(\mathrm{~m}, 1 \mathrm{H}), 6.70(\mathrm{~s}, 1 \mathrm{H}), 3.75$ $(\mathrm{s}, 3 \mathrm{H}), 3.57(\mathrm{~s}, 2 \mathrm{H})$. HRMS (ESI) $\mathrm{m} / \mathrm{z}[\mathrm{M}+1]^{+} \mathrm{C}_{15} \mathrm{H}_{3} \mathrm{l}_{3} \mathrm{~N}_{1} \mathrm{O}_{3}{ }^{+}$requires 635.8024 , found 635.8049 .

\section{NRMA-2}

2-(4-(4-hydroxy-3-isopropyl-5-((4-nitrophenyl)ethynyl)benzyl)-3,5-dimethylphenoxy)-N-methylacetamide $35 \mathrm{mg} \mathrm{NH}-3$ (0.074 mmol) yielded $18.7 \mathrm{mg}(0.038 \mathrm{mmol}, 52 \%)$ product as a yellow powder.

${ }^{1} \mathrm{H}$ NMR $(400 \mathrm{MHz}$, Chloroform-d) $\delta 8.24(\mathrm{~d}, J=8.9 \mathrm{~Hz}, 2 \mathrm{H}), 7.65(\mathrm{~d}, J=8.9 \mathrm{~Hz}, 2 \mathrm{H}), 7.04(\mathrm{~s}, 1 \mathrm{H}), 6.74(\mathrm{~s}, 1 \mathrm{H}), 6.67(\mathrm{~s}$, $2 \mathrm{H}), 5.77(\mathrm{~s}, 1 \mathrm{H}), 4.52(\mathrm{~s}, 2 \mathrm{H}), 3.93(\mathrm{~s}, 2 \mathrm{H}), 3.29($ septet, $1 \mathrm{H}), 2.94(\mathrm{~d}, J=5.0 \mathrm{~Hz}, 3 \mathrm{H}), 2.26(\mathrm{~s}, 6 \mathrm{H}), 1.26(\mathrm{t}, J=6.1 \mathrm{~Hz}$, $6 \mathrm{H})$. HRMS (ESI) $\mathrm{m} / z[\mathrm{M}+1]^{+} \mathrm{C}_{29} \mathrm{H}_{31} \mathrm{~N}_{2} \mathrm{O}_{5}{ }^{+}$requires 487.2227, found 487.2225 .

\section{NRMA-3}

2-(3-(3-((2-chloro-3-(trifluoromethyl)benzyl)(2,2-diphenylethyl)amino)propoxy)phenyl)-N-methylacetamide

$35 \mathrm{mg} \mathrm{GW} 3965$ ( $0.06 \mathrm{mmol}$ ) yielded $13.6 \mathrm{mg}(0.023 \mathrm{mmol}, 38 \%)$ product as a colorless residue. Note: during workup, the crude reaction mixture was washed with $0.5 \mathrm{M} \mathrm{NaOH}(\mathrm{aq})$ and separated on column to give the charge neutral species.

${ }^{1} \mathrm{H}$ NMR $(400 \mathrm{MHz}$, Chloroform- $d) \delta 7.50(\mathrm{~d}, J=7.1 \mathrm{~Hz}, 1 \mathrm{H}), 7.16-7.29(\mathrm{~m}, 12 \mathrm{H}), 6.96(\mathrm{t}, 1 \mathrm{H}), 6.85(\mathrm{~d}, J=7.5 \mathrm{~Hz}, 1 \mathrm{H})$, $6.74-6.64(\mathrm{~m}, 2 \mathrm{H}), 5.42(\mathrm{~s}, 1 \mathrm{H}), 4.16(\mathrm{t}, 1 \mathrm{H}), 3.81(\mathrm{~s}, 2 \mathrm{H}), 3.73(\mathrm{t}, 2 \mathrm{H}), 3.57(\mathrm{~s}, 2 \mathrm{H}), 3.17(\mathrm{~d}, J=7.7 \mathrm{~Hz}, 2 \mathrm{H}), 2.76(\mathrm{~s}$, $3 \mathrm{H}), 2.73(\mathrm{t}, 2 \mathrm{H}), 1.88$ (pentet, $2 \mathrm{H}$ ). HRMS (ESI) $\mathrm{m} / \mathrm{z}[\mathrm{M}+1]^{+} \mathrm{C}_{34} \mathrm{H}_{35} \mathrm{ClF}_{3} \mathrm{~N}_{2} \mathrm{O}_{2}{ }^{+}$requires 595.2339, found 595.2332.

\section{NRMA-4}

N-methyl-4-(1-(3,5,5,8,8-pentamethyl-5,6,7,8-tetrahydronaphthalen-2-yl)vinyl)benzamide

$35 \mathrm{mg}$ bexarotene $(0.1 \mathrm{mmol})$ yielded $29.3 \mathrm{mg}(0.081 \mathrm{mmol})$ product as a white powder. 
${ }^{1} \mathrm{H}$ NMR (400 MHz, Chloroform-d) $\delta 7.67(\mathrm{~d}, 2 \mathrm{H}), 7.33(\mathrm{~d}, 2 \mathrm{H}), 7.12(\mathrm{~s}, 1 \mathrm{H}), 7.09(\mathrm{~s}, 1 \mathrm{H}), 6.09(\mathrm{~s}, 1 \mathrm{H}), 5.78(\mathrm{~s}, 1 \mathrm{H}), 5.29$ $(\mathrm{s}, 1 \mathrm{H}), 3.01(\mathrm{~d}, J=4.7 \mathrm{~Hz}, 3 \mathrm{H}), 1.93(\mathrm{~s}, 3 \mathrm{H}), 1.69(\mathrm{~s}, 4 \mathrm{H}), 1.30(\mathrm{~s}, 6 \mathrm{H}), 1.27(\mathrm{~s}, 6 \mathrm{H})$. HRMS (ESI) $\mathrm{m} / \mathrm{z}[\mathrm{M}+1]^{+} \mathrm{C}_{25} \mathrm{H}_{32} \mathrm{~N}_{1} \mathrm{O}_{1}$ + requires 362.2478 , found 362.2486 .

\section{NRMA-5}

\section{(E)-3-(4-((E)-1-(4-hydroxyphenyl)-2-phenylbut-1-en-1-yl)phenyl)-N-methylacrylamide}

$35 \mathrm{mg} \mathrm{GW} 7604$ ( $0.094 \mathrm{mmol}$ ) yielded $8.3 \mathrm{mg}(0.021 \mathrm{mmol}, 23 \%)$ product as a yellowish residue.

${ }^{1} \mathrm{H}$ NMR $(400 \mathrm{MHz}$, Chloroform-d) $\delta 7.65(\mathrm{~d}, J=15.6 \mathrm{~Hz}, 1 \mathrm{H}), 7.44(\mathrm{~m}, 1 \mathrm{H}), 7.24(\mathrm{~m}, 2 \mathrm{H}), 7.20-7.07(\mathrm{~m}, 3 \mathrm{H}), 6.87(\mathrm{~m}$, $2 \mathrm{H}), 6.73(\mathrm{~d}, J=8.1 \mathrm{~Hz}, 1 \mathrm{H}), 6.53(\mathrm{~d}, J=8.1 \mathrm{~Hz}, 1 \mathrm{H}), 6.40(\mathrm{~d}, J=15.5 \mathrm{~Hz}, 1 \mathrm{H}), 6.22(\mathrm{~d}, J=15.6 \mathrm{~Hz}, 1 \mathrm{H}), 5.69(\mathrm{~s}, 1 \mathrm{H})$, $5.59(\mathrm{~s}, 1 \mathrm{H}), 2.96(\mathrm{~d}, J=19.8 \mathrm{~Hz}, 3 \mathrm{H}), 2.52(\mathrm{q}, 2 \mathrm{H}), 0.95(\mathrm{t}, 3 \mathrm{H})$. HRMS (ESI) $m / z[\mathrm{M}+1]^{+} \mathrm{C}_{26} \mathrm{H}_{26} \mathrm{~N}_{1} \mathrm{O}_{2}{ }^{+}$requires 384.1958, found 384.1958 .

\section{NRMA-6}

\section{N-methyl-2-(2-methyl-4-(((4-methyl-2-(4-(trifluoromethyl)phenyl)thiazol-5-} yl)methyl)thio)phenoxy)acetamide

$35 \mathrm{mg} \mathrm{GW} 501516$ (0.077 mmol) yielded $27.7 \mathrm{mg}$ (0.059 mmol, 77\%) product as an off-white powder.

${ }^{1} \mathrm{H} \mathrm{NMR}(400 \mathrm{MHz}$, Chloroform- $d) \delta 7.98(\mathrm{~d}, J=8.1 \mathrm{~Hz}, 2 \mathrm{H}), 7.67(\mathrm{~d}, J=8.2 \mathrm{~Hz}, 2 \mathrm{H}), 7.22(\mathrm{~s}, 1 \mathrm{H}), 7.19(\mathrm{~d}, 1 \mathrm{H}), 6.70(\mathrm{~d}$, $J=9.1 \mathrm{~Hz}, 1 \mathrm{H}), 6.53(\mathrm{~s}, 1 \mathrm{H}), 4.49(\mathrm{~s}, 2 \mathrm{H}), 4.14(\mathrm{~s}, 2 \mathrm{H}), 2.94(\mathrm{~d}, J=5.0 \mathrm{~Hz}, 3 \mathrm{H}), 2.24(\mathrm{~s}, 3 \mathrm{H}), 2.22(\mathrm{~s}, 3 \mathrm{H})$. HRMS (ESI) $\mathrm{m} / \mathrm{z}[\mathrm{M}+1]^{+} \mathrm{C}_{22} \mathrm{H}_{22} \mathrm{~F}_{3} \mathrm{~N}_{2} \mathrm{O}_{2} \mathrm{~S}_{2}{ }^{+}$requires 467.1069 , found 467.1067 .

\section{NRMA-7}

(S)-4-(2-(4-(2-ethoxy-3-(methylamino)-3-oxopropyl)phenoxy)ethyl)phenyl methanesulfonate $35 \mathrm{mg}$ Tesaglitazar (0.086 mmol) yielded $15.6 \mathrm{mg}(0.037 \mathrm{mmol}, 43 \%)$ product as a yellow oil.

${ }^{1} \mathrm{H} \mathrm{NMR}(400 \mathrm{MHz}$, Chloroform- $d) \delta 7.36(\mathrm{~d}, J=8.7 \mathrm{~Hz}, 2 \mathrm{H}), 7.28(\mathrm{~d}, J=8.7 \mathrm{~Hz}, 2 \mathrm{H}), 7.14(\mathrm{~d}, J=8.7 \mathrm{~Hz}, 2 \mathrm{H}), 6.81(\mathrm{~d}, J$ $=8.7 \mathrm{~Hz}, 2 \mathrm{H}), 6.48(\mathrm{~s}, 1 \mathrm{H}), 4.16(\mathrm{t}, 2 \mathrm{H}), 3.91(\mathrm{~m}, 1 \mathrm{H}), 3.44(\mathrm{~m}, 1 \mathrm{H}), 3.13(\mathrm{~s}, 3 \mathrm{H}), 3.11(\mathrm{~m}, 2 \mathrm{H}), 2.86(\mathrm{~m}, 1 \mathrm{H}), 2.79(\mathrm{~d}, J=$ $5.0 \mathrm{~Hz}, 3 \mathrm{H}), 1.15(\mathrm{t}, 3 \mathrm{H})$. HRMS (ESI) $\mathrm{m} / \mathrm{z}[\mathrm{M}+1]^{+} \mathrm{C}_{21} \mathrm{H}_{28} \mathrm{~N}_{1} \mathrm{O}_{6} \mathrm{~S}_{1}{ }^{+}$requires 422.1632 , found 422.1638 .

\section{NRMA-8}

4-chloro-N-(4-((2-methyl-1-(methylamino)-1-oxopropan-2-yl)oxy)phenethyl)benzamide

$35 \mathrm{mg}$ Bezafibrate $(0.097 \mathrm{mmol}$ ) yielded $29.8 \mathrm{mg}$ (0.079 $\mathrm{mmol}, 82 \%)$ product as a white powder.

${ }^{1} \mathrm{H} \mathrm{NMR}(400 \mathrm{MHz}$, Chloroform-d) $\delta 7.63(\mathrm{~d}, J=8.6 \mathrm{~Hz}, 2 \mathrm{H}), 7.38(\mathrm{~d}, J=8.6 \mathrm{~Hz}, 2 \mathrm{H}), 7.12(\mathrm{~d}, J=8.5 \mathrm{~Hz}, 2 \mathrm{H}), 6.86(\mathrm{~d}, J$ $=8.5 \mathrm{~Hz}, 2 \mathrm{H}), 6.76(\mathrm{~s}, 1 \mathrm{H}), 6.21(\mathrm{~s}, 1 \mathrm{H}), 3.67(\mathrm{q}, J=6.1 \mathrm{~Hz}, 2 \mathrm{H}), 2.90(\mathrm{~m}, 2 \mathrm{H}), 2.88(\mathrm{~s}, 3 \mathrm{H}), 1.48(\mathrm{~s}, 6 \mathrm{H})$. HRMS (ESI) $\mathrm{m} / \mathrm{z}[\mathrm{M}+1]^{+} \mathrm{C}_{20} \mathrm{H}_{24} \mathrm{ClN}_{2} \mathrm{O}_{3}{ }^{+}$requires 375.1470, found 375.1472.

\section{NRMA-9}

2-(3-chloro-4-((3-((7-propyl-3-(trifluoromethyl)benzo[d]isoxazol-6-yl)oxy)propyl)thio)phenyl)-Nmethylacetamide

$35 \mathrm{mg}$ F3MethylAA (0.072 mmol) yielded $11.2 \mathrm{mg}(0.022 \mathrm{mmol}$, 31\%) product as a white powder.

${ }^{1} \mathrm{H}$ NMR (400 MHz, Chloroform-d) $\delta 7.58(\mathrm{~d}, J=8.8 \mathrm{~Hz}, 1 \mathrm{H}), 7.31(\mathrm{~m}, J=3.9 \mathrm{~Hz}, 2 \mathrm{H}), 7.15(\mathrm{~d}, J=9.9 \mathrm{~Hz}, 1 \mathrm{H}), 7.07(\mathrm{~d}, J$ $=8.8 \mathrm{~Hz}, 1 \mathrm{H}), 5.52(\mathrm{~s}, 1 \mathrm{H}), 4.26(\mathrm{t}, 2 \mathrm{H}), 3.50(\mathrm{~s}, 2 \mathrm{H}), 3.20(\mathrm{t}, J=7.1 \mathrm{~Hz}, 2 \mathrm{H}), 2.94(\mathrm{t}, 2 \mathrm{H}), 2.80(\mathrm{~d}, J=4.8 \mathrm{~Hz}, 3 \mathrm{H}), 2.24$ 
(pentet, $2 \mathrm{H}$ ), $1.72($ sextet, $J=7.5 \mathrm{~Hz}, 2 \mathrm{H}), 0.98(\mathrm{t}, 3 \mathrm{H})$. HRMS (ESI) $m / z[\mathrm{M}+1]^{+} \mathrm{C}_{23} \mathrm{H}_{25} \mathrm{ClF}_{3} \mathrm{~N}_{2} \mathrm{O}_{3} \mathrm{~S}_{1}+$ requires 501.1221 , found 501.1218 .

\section{NRMA-10}

\section{6-((4,4-dimethylthiochroman-6-yl)ethynyl)-N-methylnicotinamide}

$35 \mathrm{mg}$ Tazarotenic acid (0.11 mmol) yielded $29.2 \mathrm{mg}(0.087 \mathrm{mmol}, 79 \%)$ product as a yellow powder.

${ }^{1} \mathrm{H}$ NMR (400 MHz, Chloroform-d) $\delta 8.95(\mathrm{~s}, 1 \mathrm{H}), 8.12(\mathrm{dd}, J=8.1,2.2 \mathrm{~Hz}, 1 \mathrm{H}), 7.64-7.54(\mathrm{~m}, 2 \mathrm{H}), 7.31-7.21(\mathrm{~m}$, $1 \mathrm{H}), 7.08(\mathrm{~d}, J=8.1 \mathrm{~Hz}, 1 \mathrm{H}), 6.54(\mathrm{~s}, 1 \mathrm{H}), 3.10-3.02(\mathrm{~m}, 2 \mathrm{H}), 3.05(\mathrm{~s}, 3 \mathrm{H}), 2.00-1.92(\mathrm{~m}, 2 \mathrm{H}), 1.34(\mathrm{~s}, 6 \mathrm{H}) . \mathrm{HRMS}$ (ESI) $m / z[M+1]^{+} \mathrm{C}_{20} \mathrm{H}_{21} \mathrm{~N}_{2} \mathrm{O}_{1} \mathrm{~S}_{1}{ }^{+}$requires 337.1369, found 337.1374 .

\section{Associated Content}

\section{Supporting Information}

The Supporting Information contains tabulated physicochemical properties of the series, mass spectrometry information, and ${ }^{1} \mathrm{H}$ NMR spectra.

\section{Author Information}

\section{Corresponding authors}

*E-mail: scanlant@ohsu.edu

\section{ORCHID}

Skylar J. Ferrara https://orcid.org/0000-0001-7826-5621

Thomas S. Scanlan https://orcid.org/0000-0003-2612-5445

\section{Funding}

This work was supported by the National Institutes of Health (DK 052798, T.S.S., and T32DKoo7680, support to S.J.F.).

\section{Notes}

The authors declare the following competing financial interest(s): S.J.F. and T.S.S. are inventors of a licensed patent application claiming central nervous system-penetrating prodrugs of nuclear receptor modulators and their uses. T.S.S. is a founder of Autobahn Therapeutics.

\section{Acknowledgements}

We thank Lisa Bleyle (OHSU Bioanalytical Shared Resource/ Pharmacokinetics Core) for technical assistance with LC-MS/ MS, Prof. Benjamin Cravatt (Scripps Research Institute) for the FAAH-KO mice, and Dr. J. Matthew Meinig for preparation and isolation of mouse liver $\mathrm{Sg}$ fractions.

\section{Abbreviations}

AUC, area under the curve, i.p. intraperitoneal; RT-qPCR, real-time quantitative polymerase chain reaction; WT, wild type

\section{References}


1. Skerrett, R.; Malm, T.; Landreth, G., Nuclear receptors in neurodegenerative diseases. Neurobiology of Disease 2014, 72, 104-116.

2. Moutinho, M.; Codocedo, J. F.; Puntambekar, S. S.; Landreth, G. E., Nuclear Receptors as Therapeutic Targets for Neurodegenerative Diseases: Lost in Translation. Annual Review of Pharmacology and Toxicology 2019, 59 (1), 237-261.

3. Kabat, G. C.; Etgen, A. M.; Rohan, T. E., Do Steroid Hormones Play a Role in the Etiology of Glioma? Cancer Epidemiology Biomarkers \&amp; Prevention 2010, 19 (10), 2421-2427.

4. Littleton-Kearney, M. T.; Ostrowski, N. L.; Cox, D. A.; Rossberg, M. I.; Hurn, P. D., Selective Estrogen Receptor Modulators: Tissue Actions and Potential for CNS Protection. CNS Drug Reviews 2002, 8 (3), 309-330.

5. Kim, C.-H.; Han, B.-S.; Moon, J.; Kim, D.-J.; Shin, J.; Rajan, S.; Nguyen, Q. T.; Sohn, M.; Kim, W.-G.; Han, M.; Jeong, I.; Kim, K.-S.; Lee, E.-H.; Tu, Y.; Naffin-Olivos, J. L.; Park, C.-H.; Ringe, D.; Yoon, H. S.; Petsko, G. A.; Kim, K.-S., Nuclear receptor Nurr1 agonists enhance its dual functions and improve behavioral deficits in an animal model of Parkinson's disease. Proceedings of the National Academy of Sciences 2015, 112 (28), 8756-8761.

6. Overington, J. P.; Al-Lazikani, B.; Hopkins, A. L., How many drug targets are there? Nature Reviews Drug Discovery 2006, 5 (12), 993-996.

7. Moore, J. T.; Collins, J. L.; Pearce, K. H., The Nuclear Receptor Superfamily and Drug Discovery. ChemMedChem 2006, 1 (5), 504-523.

8. Ana Maria, A.; Oscar Andréas, M.-R.; Haider, N. B., Role of Nuclear Receptors in Central Nervous System Development and Associated Diseases. Journal of Experimental Neuroscience 2015, 9s2, JEN.S25480.

9. Moutinho, M.; Landreth, G. E., Therapeutic potential of nuclear receptor agonists in Alzheimer's disease. Journal of Lipid Research 2017, 58 (10), 1937-1949.

10. Meinig, J. M.; Ferrara, S. J.; Banerji, T.; Banerji, T.; Sanford-Crane, H. S.; Bourdette, D.; Scanlan, T. S., Targeting Fatty-Acid Amide Hydrolase with Prodrugs for CNS-Selective Therapy. ACS Chemical Neuroscience 2017, 8 (11), 2468-2476.

11. Meinig, J. M.; Ferrara, S. J.; Banerji, T.; Banerji, T.; Sanford-Crane, H. S.; Bourdette, D.; Scanlan, T. S., Structure-Activity Relationships of Central Nervous System Penetration by Fatty Acid Amide Hydrolase (FAAH)-Targeted Thyromimetic Prodrugs. ACS Medicinal Chemistry Letters 2019, 10 (1), 111116.

12. Hartley, M. D.; Banerji, T.; Tagge, I. J.; Kirkemo, L. L.; Chaudhary, P.; Calkins, E.; Galipeau, D.; Shokat, M. D.; DeBell, M. J.; Van Leuven, S.; Miller, H.; Marracci, G.; Pocius, E.; Banerji, T.; Ferrara, S. J.; Meinig, J. M.; Emery, B.; Bourdette, D.; Scanlan, T. S., Myelin repair stimulated by CNS-selective thyroid hormone action. JCl Insight 2019, 4 (8).

13. Hartley, M. D.; Shokat, M. D.; DeBell, M. J.; Banerji, T.; Kirkemo, L. L.; Scanlan, T. S., Pharmacological Complementation Remedies an Inborn Error of Lipid Metabolism. Cell Chemical Biology 2020.

14. McKinney, M. K.; Cravatt, B. F., Structure and function of fatty acid amide hydrolase. Annual Review of Biochemistry 2005, 74 (1), 411-432.

15. Giang, D. K.; Cravatt, B. F., Molecular characterization of human and mouse fatty acid amide hydrolases. Proceedings of the National Academy of Sciences 1997, 94 (6), 2238-2242.

16. Li, Y.; Lambert, M. H.; Xu, H. E., Activation of Nuclear Receptors: A Perspective from Structural Genomics. Structure 2003, 11 (7), 741-746.

17. Aldeghi, M.; Malhotra, S.; Selwood, D. L.; Chan, A. W. E., Two- and Three-dimensional Rings in Drugs. Chemical Biology \& Drug Design 2014, 83 (4), 450-461.

18. Lipinski, C. A., Drug-like properties and the causes of poor solubility and poor permeability. Journal of Pharmacological and Toxicological Methods 2000, 44 (1), 235-249. 
19. Ahn, K.; Johnson, D. S.; Mileni, M.; Beidler, D.; Long, J. Z.; McKinney, M. K.; Weerapana, E.; Sadagopan, N.; Liimatta, M.; Smith, S. E.; Lazerwith, S.; Stiff, C.; Kamtekar, S.; Bhattacharya, K.; Zhang, Y.; Swaney, S.; Van Becelaere, K.; Stevens, R. C.; Cravatt, B. F., Discovery and Characterization of a Highly Selective FAAH Inhibitor that Reduces Inflammatory Pain. Chemistry \& Biology 2009, 16 (4), 411-420. 20. Meyers, J.; Carter, M.; Mok, N. Y.; Brown, N., On the origins of three-dimensionality in drug-like molecules. Future Medicinal Chemistry 2016, 8 (14), 1753-1767.

21. Corona, J. C.; Duchen, M. R., PPARY as a therapeutic target to rescue mitochondrial function in neurological disease. Free Radical Biology and Medicine 2016, 100, 153-163.

22. Jiang, Q.; Heneka, M.; Landreth, G. E., The Role of Peroxisome Proliferator-Activated Receptor- $\gamma$ PPARY) in Alzheimer's Disease. CNS Drugs 2008, 22 (1), 1-14.

23. Moosecker, S.; Gomes, P.; Dioli, C.; Yu, S.; Sotiropoulos, I.; Almeida, O. F. X., Activated PPARY Abrogates Misprocessing of Amyloid Precursor Protein, Tau Missorting and Synaptotoxicity. Frontiers in Cellular Neuroscience 2019, 13 (239).

24. Villapol, S., Roles of Peroxisome Proliferator-Activated Receptor Gamma on Brain and Peripheral Inflammation. Cellular and Molecular Neurobiology 2018, 38 (1), 121-132.

25. Hamrén, B.; Öhman, K. P.; Svensson, M. K.; Karlsson, M. O., Pharmacokinetic-Pharmacodynamic Assessment of the Interrelationships Between Tesaglitazar Exposure and Renal Function in Patients With Type 2 Diabetes Mellitus. The Journal of Clinical Pharmacology 2012, 52 (9), 1317-1327.

26. Kalliora, C.; Kyriazis, I. D.; Oka, S.-i.; Lieu, M. J.; Yue, Y.; Area-Gomez, E.; Pol, C. J.; Tian, Y.; Mizushima, W.; Chin, A.; Scerbo, D.; Schulze, P. C.; Civelek, M.; Sadoshima, J.; Madesh, M.; Goldberg, I. J.; Drosatos, K., Dual PPAR $\alpha / \gamma$ activation inhibits SIRT1-PGC1 $\alpha$ axis and causes cardiac dysfunction. JCI Insight 2019, 4 (17).

27. Endres, K.; Deller, T., Regulation of Alpha-Secretase ADAM10 In vitro and In vivo: Genetic, Epigenetic, and Protein-Based Mechanisms. Frontiers in Molecular Neuroscience 2017, 10 (56).

28. Duvic, M.; Nagpal, S.; Asano, A. T.; Chandraratna, R. A. S., Molecular mechanisms of tazarotene action in psoriasis. Journal of the American Academy of Dermatology 1997, 37 (2, Part 3), S18-S24.

29. Placzek, A. T.; Scanlan, T. S., New synthetic routes to thyroid hormone analogs: d6-sobetirome, 3H-sobetirome, and the antagonist NH-3. Tetrahedron 2015, 71 (35), 5946-5951.

30. Cravatt, B. F.; Demarest, K.; Patricelli, M. P.; Bracey, M. H.; Giang, D. K.; Martin, B. R.; Lichtman, A. H., Supersensitivity to anandamide and enhanced endogenous cannabinoid signaling in mice lacking fatty acid amide hydrolase. Proceedings of the National Academy of Sciences 2001, 98 (16), 9371-9376.

31. Ferrara, S. J.; Meinig, J. M.; Placzek, A. T.; Banerji, T.; McTigue, P.; Hartley, M. D.; Sanford-Crane, H. S.; Banerji, T.; Bourdette, D.; Scanlan, T. S., Ester-to-amide rearrangement of ethanolamine-derived prodrugs of sobetirome with increased blood-brain barrier penetration. Bioorganic \& Medicinal Chemistry 2017, 25 (10), 2743-2753.

32. Pfaffl, M. W., A new mathematical model for relative quantification in real-time RT-PCR. Nucleic Acids Research 2001, 29 (9), e45-e45.

33. Ferrara, S. J.; Bourdette, D.; Scanlan, T. S., Hypothalamic-Pituitary-Thyroid Axis Perturbations in Male Mice by CNS-Penetrating Thyromimetics. Endocrinology 2018, 159 (7), 2733-2740.

34. Esmaeili, M. A.; Yadav, S.; Gupta, R. K.; Waggoner, G. R.; Deloach, A.; Calingasan, N. Y.; Beal, M. F.; Kiaei, M., Preferential PPAR- $\alpha$ activation reduces neuroinflammation, and blocks neurodegeneration in vivo. Hum Mol Genet 2016, 25 (2), 317-327.

35. Kitaoka, K.; Shimizu, N.; Ono, K.; Chikahisa, S.; Nakagomi, M.; Shudo, K.; Ishimura, K.; Séi, H.; Yoshizaki, K., The retinoic acid receptor agonist Am80 increases hippocampal ADAM10 in aged SAMP8 mice. Neuropharmacology 2013, 72, 58-65.

36. Qiang, L.; Wang, L.; Kon, N.; Zhao, W.; Lee, S.; Zhang, Y.; Rosenbaum, M.; Zhao, Y.; Gu, W.; Farmer, Stephen R.; Accili, D., Brown Remodeling of White Adipose Tissue by SirT1-Dependent Deacetylation of Ppary. Cell 2012, 150 (3), 620-632. 
37. Shih, D. M.; Wang, Z.; Lee, R.; Meng, Y.; Che, N.; Charugundla, S.; Qi, H.; Wu, J.; Pan, C.; Brown, J. M.; Vallim, T.; Bennett, B. J.; Graham, M.; Hazen, S. L.; Lusis, A. J., Flavin containing monooxygenase 3 exerts broad effects on glucose and lipid metabolism and atherosclerosis. Journal of Lipid Research 2015, 56 (1), 22-37.

38. Kodani, S. D.; Wan, D.; Wagner, K. M.; Hwang, S. H.; Morisseau, C.; Hammock, B. D., Design and Potency of Dual Soluble Epoxide Hydrolase/Fatty Acid Amide Hydrolase Inhibitors. ACS Omega 2018, 3 (10), 14076-14086.

\section{For Table of Contents Only}

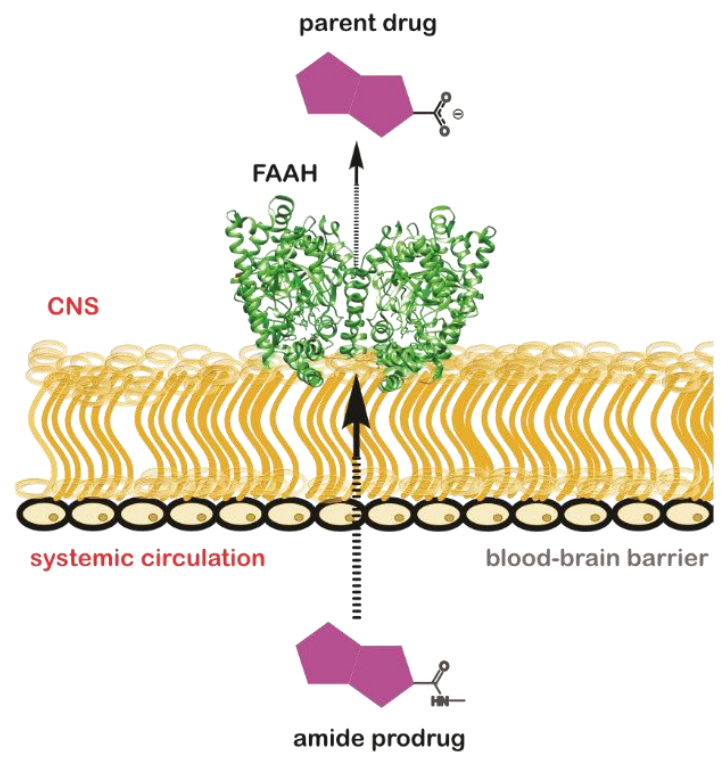




\section{A CNS-targeting prodrug strategy for nuclear receptor modulators}

Skylar J. Ferrara and Thomas S. Scanlan*

Department of Chemical Physiology and Biochemistry, Oregon Health \& Science University, 3181 SW Sam Jackson Park Road, Portland, Oregon 97239, United States

*Corresponding author: scanlant@ohsu.edu

\section{CONTENTS}

Supplementary Table 1.....................................................

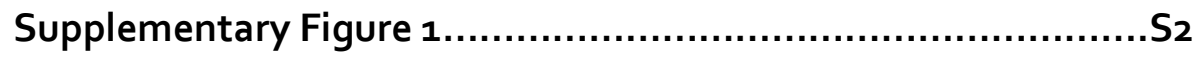

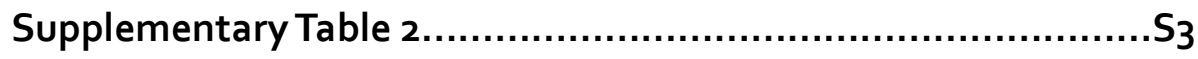

Copies of ${ }^{1} \mathrm{H}$ NMR Spectra.................................................

Table S1: Physicochemical properties for the series of prodrugs calculated using ChemAxon's Chemicalize program (Cambridge, MA, USA)

\begin{tabular}{|c|c|c|c|c|c|c|c|c|c|c|c|c|}
\hline Compound & LogP & CLogP & MW & FSp & tPSA & MR & MP & HBA & HBD & RB & $\begin{array}{c}\text { Van der Waals } \\
\text { volume }\end{array}$ & $\begin{array}{c}\text { Van der Waals } \\
\text { surface area }\end{array}$ \\
\hline NRMA-1 & $5.01^{\text {a }}$ & 4.88 & 634.978 & 0.13 & 58.56 & 112.39 & 43.99 & 2 & 2 & 4 & 308.14 & 451.3 \\
\hline NRMA-2 & 6.83 & 6.73 & 486.568 & 0.28 & 101.7 & 135.47 & 52.69 & 5 & 2 & 9 & 451.69 & 730.18 \\
\hline NRMA-3 & 7.67 & 7.87 & 595.1 & 0.26 & 41.57 & 162.76 & 61.8 & 3 & 1 & 14 & 530.24 & 849.18 \\
\hline NRMA-4 & 6.36 & 7.17 & 361.529 & 0.4 & 29.1 & 123.84 & 43.77 & 1 & 1 & 3 & 369.28 & 608.2 \\
\hline NRMA-5 & 5.77 & 5.8 & 383.491 & 0.12 & 49.33 & 129.65 & 45.86 & 2 & 2 & 6 & 365.89 & 565.22 \\
\hline NRMA-6 & 5.3 & 5.27 & 466.54 & 0.27 & 51.22 & 128.6 & 44.81 & 3 & 1 & 8 & 385.13 & 616 \\
\hline NRMA-7 & 2.56 & 2.34 & 421.51 & 0.38 & 90.93 & 110.24 & 43.86 & 5 & 1 & 11 & 382.39 & 645.45 \\
\hline NRMA-8 & 3.4 & 3.17 & 374.87 & 0.3 & 67.43 & 102.68 & 39.41 & 3 & 2 & 7 & 339.58 & 554.12 \\
\hline NRMA-9 & 5.91 & 6.44 & 500.96 & 0.39 & 64.36 & 124.73 & 47.79 & 3 & 1 & 11 & 412.61 & 670.00 \\
\hline NRMA-10 & 3.93 & 4.89 & 336.45 & 0.3 & 41.99 & 95.08 & 37.71 & 2 & 1 & 3 & 309.8 & 483.07 \\
\hline
\end{tabular}

'Red numbers indicate values which violate Lipinski's Rules 


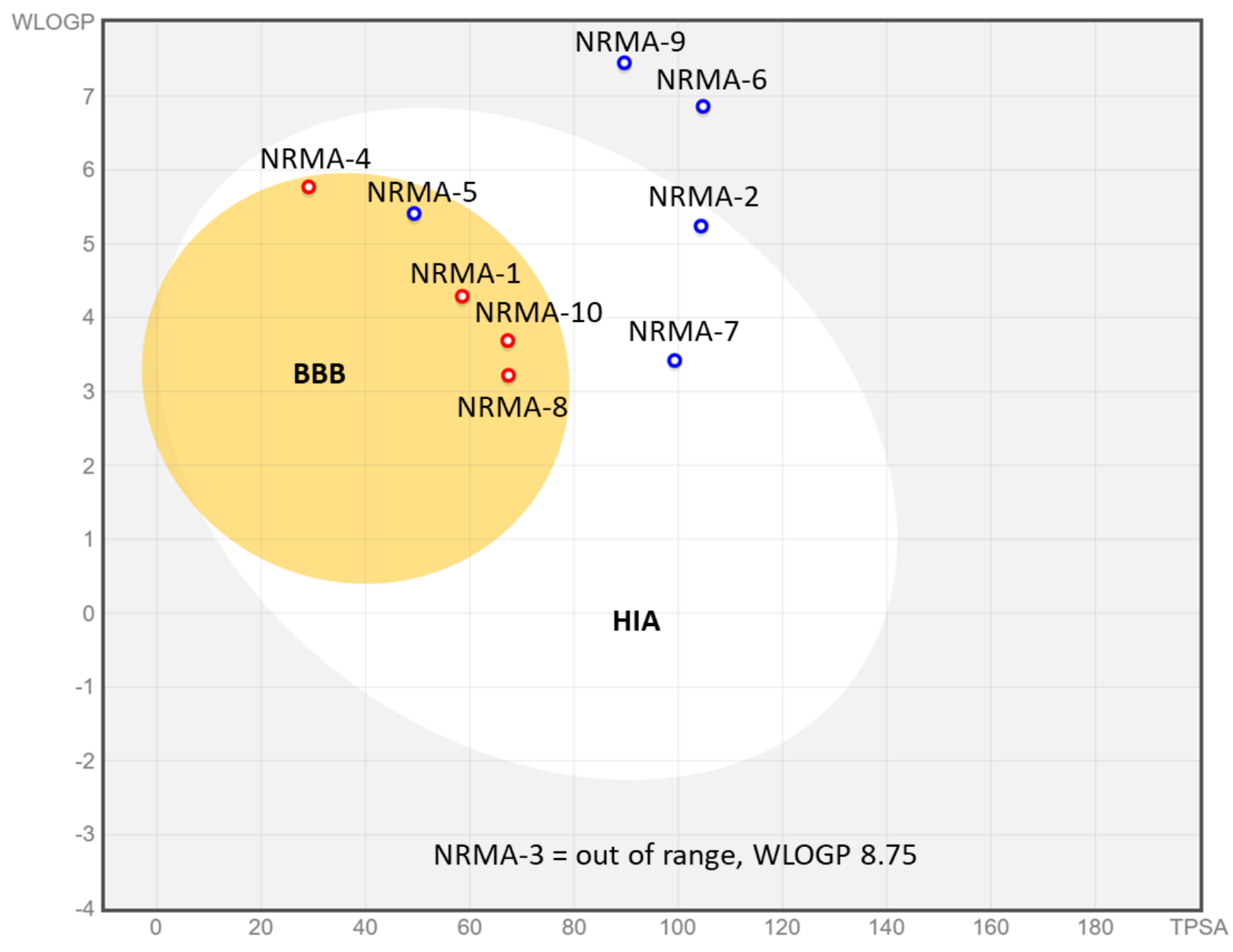

Figure S1: Boiled egg plot generated using SwissADME (Lausanne, Switzerland). NRMA-3 lies out of plot range with a WLOGP of 8.75. BBB (predicted blood-brain barrier penetrance) and HIA (human gastrointestinal absorbance) are advanced parameters generated by SwissADME. 
Table S2: LC-MS/MS multiple reaction monitoring (MRM) transitions and settings for bioanalytical quantification of the series of parent drugs

\begin{tabular}{|c|c|c|c|c|c|c|c|}
\hline Compound $^{a}$ & $\begin{array}{c}\text { RetentionTime } \\
\text { (min.) }\end{array}$ & Q1 Mass & Q3 Mass & DP & EP & CE & CXP \\
\hline D6 GC-1 & 3.95 & 333.0 & 275.2 & -90 & -10 & -34 & -5 \\
\hline D6 GC-1 & 3.95 & 333.0 & 141.1 & -90 & -10 & -48 & -7 \\
\hline F3MethylAA & 5.2 & 486.1 & 243.8 & -40 & -10 & -22 & -17 \\
\hline F3MethylAA & 5.2 & 486.1 & 442.3 & -40 & -10 & -12 & -5 \\
\hline TRIAC & 4.72 & 620.8 & 126.8 & -30 & -10 & -26 & -7 \\
\hline TRIAC & 4.72 & 620.8 & 576.8 & -30 & -10 & -10 & -11 \\
\hline $\mathrm{NH}_{3}$ & 5.19 & 472.3 & 413.9 & -85 & -10 & -34 & -9 \\
\hline $\mathrm{NH}_{3}$ & 5.19 & 472.3 & 428.2 & -85 & -10 & -30 & -7 \\
\hline $\mathrm{GW}_{501516}$ & 4.64 & 452 & 137.8 & -80 & -10 & -48 & -7 \\
\hline$G_{501516}$ & 4.64 & 452 & 394 & -80 & -10 & -22 & -9 \\
\hline$G_{3965}$ & 4.5 & 580.3 & 178.9 & -75 & -10 & -28 & -13 \\
\hline GW3965 & 4.5 & 580.3 & 107 & -75 & -10 & -88 & -13 \\
\hline GW7604 & 4.12 & 369.2 & 325 & -100 & -10 & -28 & -11 \\
\hline GW7604 & 4.12 & 369.2 & 309 & -100 & -10 & -30 & -15 \\
\hline $\begin{array}{c}\text { Tazarotenic } \\
\text { Acid }\end{array}$ & 4.21 & 322 & 201 & -105 & -10 & -56 & -15 \\
\hline Bexarotene & 5.48 & 347.1 & 303.1 & -100 & -10 & -32 & -7 \\
\hline Bezafibrate & 3.42 & 360 & 273.7 & -80 & -10 & -24 & -47 \\
\hline Bezafibrate & 3.42 & 360 & 153.8 & -80 & -10 & -42 & -7 \\
\hline Tesaglitazar & 3.68 & 407 & 329 & -60 & -10 & -20 & -9 \\
\hline Tesaglitazar & 3.68 & 407 & 162.8 & -60 & -10 & -40 & -15 \\
\hline
\end{tabular}

aThe scheduled MRM transitions monitored are listed in the table above; the bold are used for quantification, normal text are qualifying ions where available. Compounds were infused individually and instrument parameters were optimized for each MRM transition.

\section{Copies of ${ }^{1} \mathrm{H}$ NMR Spectra}

*Note: MestreNova-generated purple peak label boxes were manually edited out of some spectra for clarity 

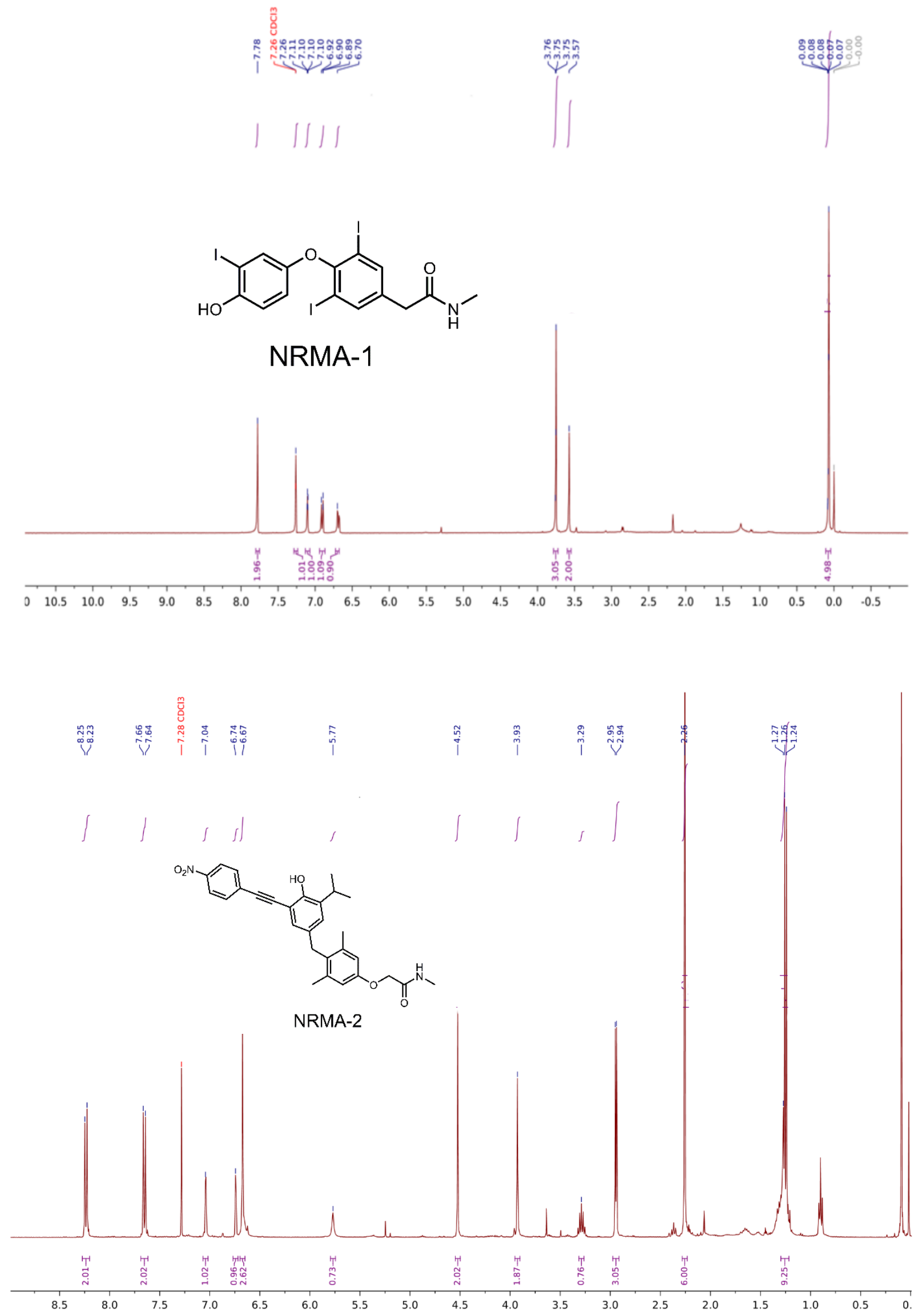

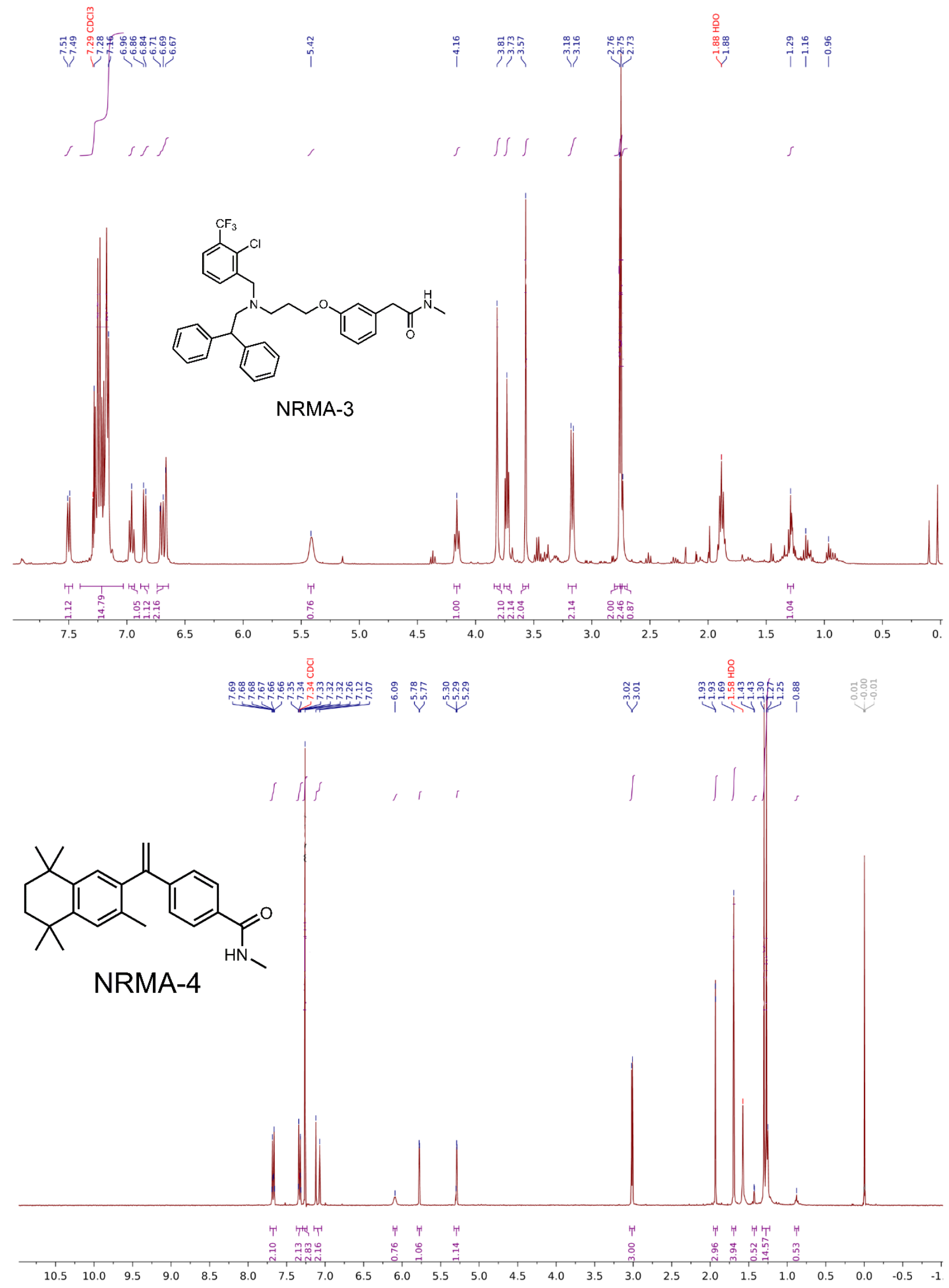

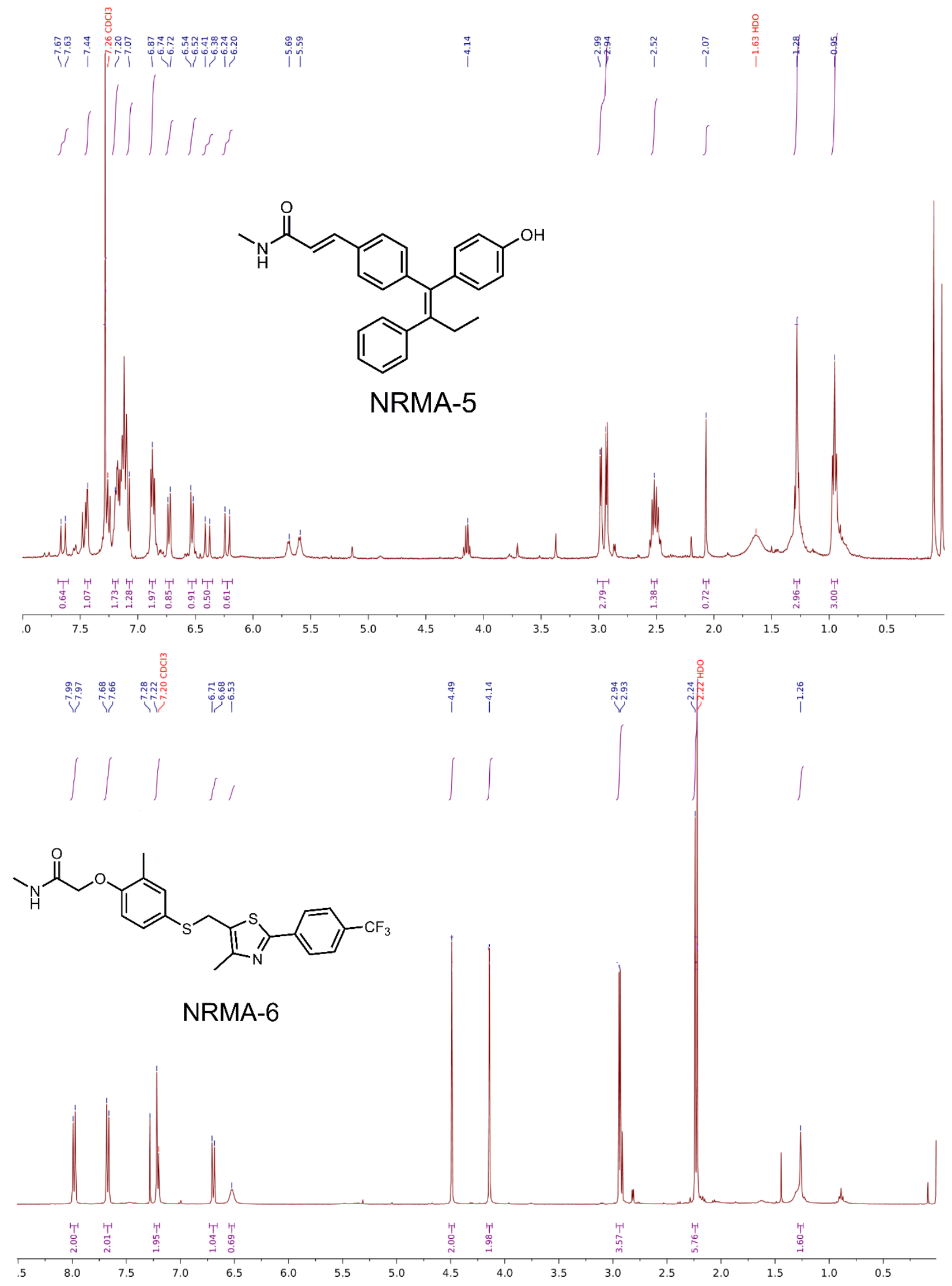


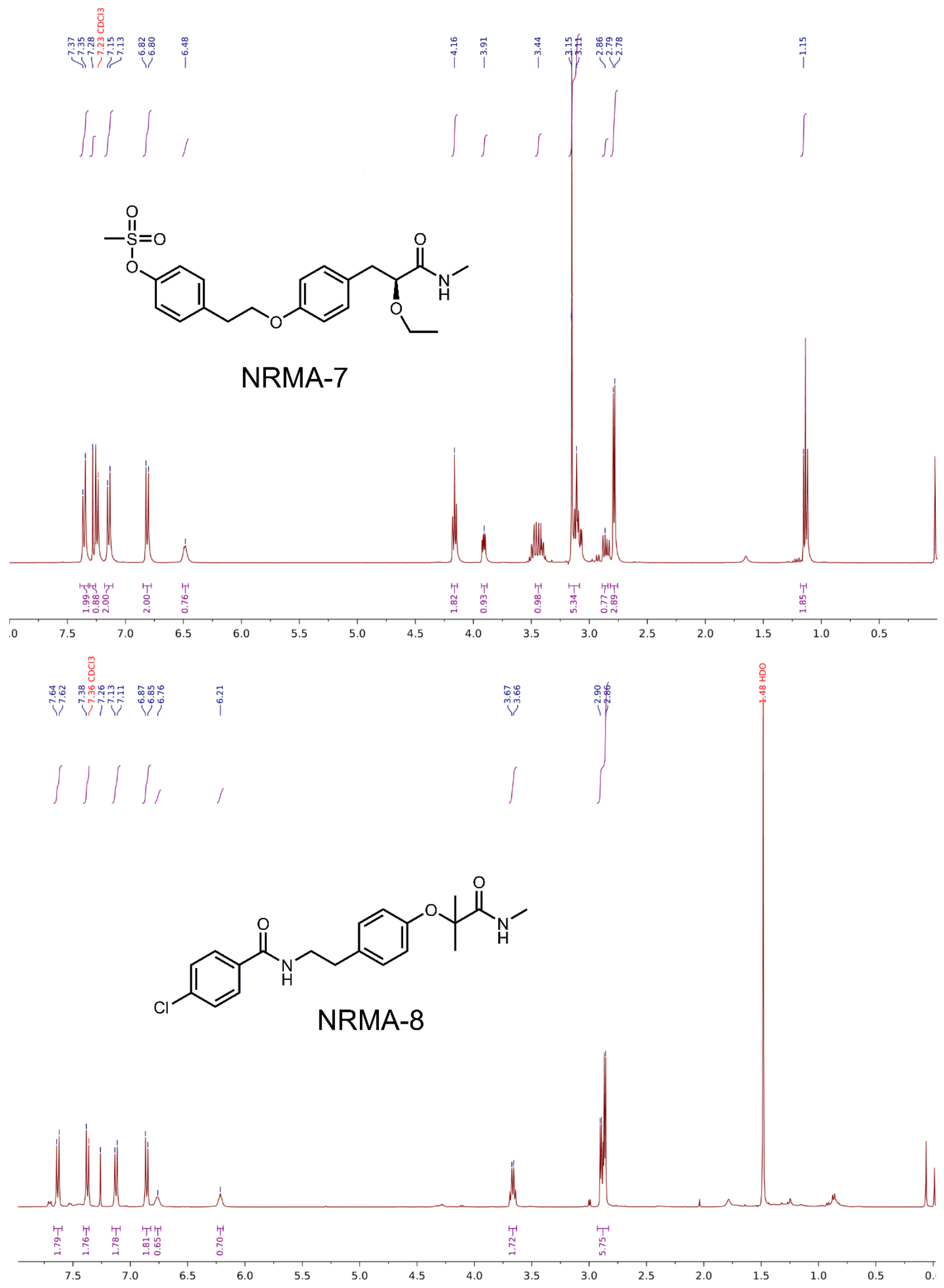




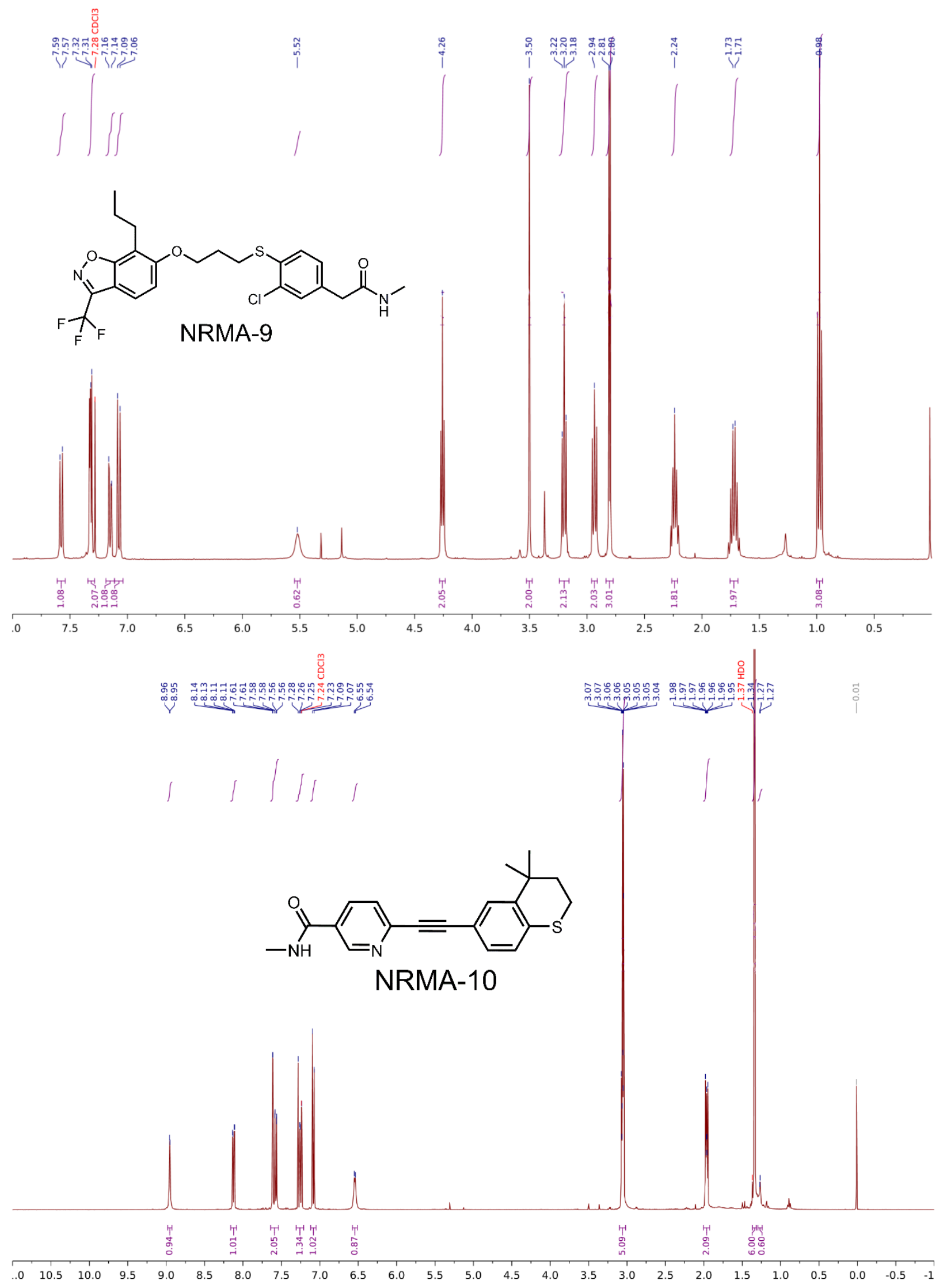

